\title{
DD04107-Derived neuronal exocytosis inhibitor peptides: Evidences for synaptotagmin-1 as a putative target
}

\author{
Daniel Butrón $^{\mathrm{a}}$, Héctor Zamora-Carreras ${ }^{\mathrm{b}, 1}$, Isabel Devesa ${ }^{\mathrm{c}}$, Miguel A. Treviño ${ }^{\mathrm{b}}$, \\ Olga Abian $^{\mathrm{d}, \mathrm{e}, \mathrm{f}, \mathrm{g}, \mathrm{h}}$, Adrián Velázquez-Campoy ${ }^{\mathrm{d}, \mathrm{e}, \mathrm{f}, \mathrm{g}, \mathrm{i}}$, M. Ángeles Bonache ${ }^{\mathrm{a}}$, Laura Lagartera ${ }^{\mathrm{a}}$, \\ Mercedes Martín-Martínez ${ }^{a}$, Sara González-Rodríguez ${ }^{g}$, Ana Baamonde ${ }^{j}$, \\ Asia Fernández-Carvajal ${ }^{c}$, Antonio Ferrer-Montiel ${ }^{\mathrm{c}, *}$, M. Ángeles Jiménez ${ }^{\mathrm{b}, *}$, \\ Rosario González-Muñiz ${ }^{\text {a, }}$ \\ a Instituto de Química Médica (IQM-CSIC), Juan de la Cierva 3, 28006 Madrid, Spain \\ ${ }^{\mathrm{b}}$ Instituto de Química Física Rocasolano (IQFR-CSIC), Serrano 119, 28006 Madrid, Spain \\ ${ }^{\mathrm{c}}$ IDiBE, Universidad Miguel Hernández, Avda. de la Universidad $s / n, 03202$ Elche, Spain \\ ${ }^{\mathrm{d}}$ Institute of Biocomputation and Physics of Complex Systems (BIFI), Joint Units IQFR-CSIC-BIFI, and GBsC-CSIC-BIFI, Universidad de Zaragoza, 50018 Zaragoza, \\ Spain \\ e Departamento de Bioquímica y Biología Molecular y Celular, Universidad de Zaragoza, 50009 Zaragoza, Spain \\ ${ }^{\mathrm{f}}$ Biomedical Research Networking Centre for Liver and Digestive Diseases (CIBERehd), Madrid, Spain \\ ${ }^{\mathrm{g}}$ Aragon Institute for Health Research (IIS Aragon), 50009 Zaragoza, Spain \\ ${ }^{\mathrm{h}}$ Aragon Health Sciences Institute (IACS), 50009 Zaragoza, Spain \\ ${ }^{\mathrm{i}}$ ARAID Foundation, Government of Aragon, 50018 Zaragoza, Spain \\ ${ }^{\mathrm{j}}$ Facultad de Medicina, Instituto Universitario de Oncología del Principado de Asturias (IUOPA), Universidad de Oviedo, Julián Clavería 6, 33006 Oviedo, Asturias, \\ Spain
}

\section{A R T I C L E I N F O}

\section{Keywords:}

DD04107

Ala-scan

Exocytosis

Synaptotagmin-1

CGRP

NMR

Isothermal titration calorimetry

Molecular modeling

Analgesia

\begin{abstract}
A B S T R A C T
The analgesic peptide DD04107 (Pal-EEMQRR- $\mathrm{NH}_{2}$ ) and its acetylated analogue inhibit $\alpha$-calcitonin gene-related peptide ( $\alpha$-CGRP) exocytotic release from primary sensory neurons. Examining the crystal structure of the SNARE-Synaptotagmin-1(Syt1) complex, we hypothesized that these peptides could inhibit neuronal exocytosis by binding to Syt1, hampering at least partially its interaction with the SNARE complex. To address this hypothesis, we first interrogate the role of individual side-chains on the inhibition of $\alpha$-CGRP release, finding that E1, M3, Q4 and R6 residues were crucial for activity. CD and NMR conformational analysis showed that linear peptides have tendency to adopt $\alpha$-helical conformations, but the results with cyclic analogues indicated that this secondary structure is not needed for activity. Isothermal titration calorimetry (ITC) measurements demonstrate a direct interaction of some of these peptides with Syt1-C2B domain, but not with Syt7-C2B region, indicating selectivity. As expected for a compound able to inhibit $\alpha$-CGRP release, cyclic peptide derivative Pal-E-cyclo $[E M Q K] \mathrm{R}-\mathrm{NH}_{2}$ showed potent in vivo analgesic activity, in a model of inflammatory pain. Molecular dynamics simulations provided a model consistent with $\mathrm{K}_{\mathrm{D}}$ values for the interaction of peptides with Syt1-C2B domain, and with their biological activity. Altogether, these results identify Syt1 as a potential new analgesic target.
\end{abstract}

Abbreviations: BoNTA, botulinum neurotoxin A; CFA, Freund's adjuvant; DD04107, Palmitoyl-EEMQRR-NH 2 ; DIEA, diisopropylethylamine; EDT, ethanedithiol;

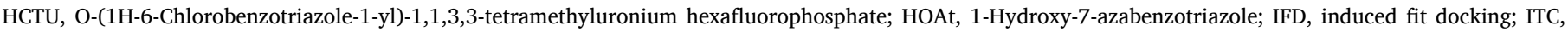

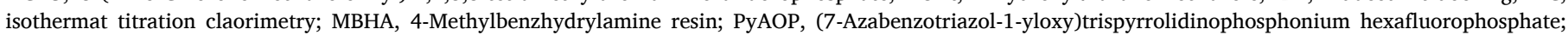

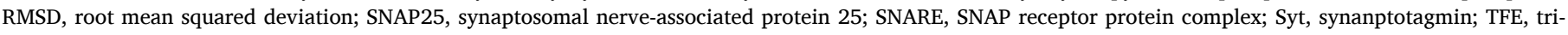
fluoroethanol; TRPV1, transient receptor potential vanilloid type 1; VAMP2, vesicle-associated membrane protein 2.

* Corresponding authors.

E-mail addresses: aferrer@umh.es (A. Ferrer-Montiel), majimenez@iqfr.csic.es (M.Á. Jiménez), iqmg313@iqm.csic.es (R. González-Muñiz).

1 Present address: Department of Immunology, Ophthalmology and ENT, School of Medicine, Universidad Complutense de Madrid, Plaza de Ramón y Cajal s/n, 28040 Madrid, Spain. 


\section{Introduction}

Pain is an unpleasant physical distress produced by tissue or neural damage or by certain diseases [1]. Often, it remains even after resolution of the initial damage or disease, thus chronifying and becoming a disease itself [2]. Because of a significant subjective component, pain is difficult to be objectively measured, poorly understood in many cases, and particularly resistant to current therapies [2]. Most common analgesic drugs, nonsteroidal anti-inflammatory drugs (NSAIDs) and opioids, do not provide acceptable pain relief for chronic pain, particularly neuropathic pain, and their use is limited because of unwanted side effects, including the potential of dependence and drug abuse for opioids [3]. In the past, the discovery of a plethora of molecular mediators involved in pain signaling and transmission identified potential novel molecular targets for drug intervention and to interrogate specific pain mechanisms [4].

As a pivotal case in point, it is well established that the $\alpha$-calcitonin gene related peptide ( $\alpha$-CGRP), through the interaction with specific receptors, contributes to neurogenic inflammation and nociceptor sensitization [5,6], playing a main role in inflammatory chronic pain $[7,8]$. Consequently, botulinum neurotoxin A (BoNTA), a neurotoxin that blocks the exocytotic release of calcitonin gen-related peptide $(\alpha$-CGRP) and other neurotransmitters by targetting the SNARE neuronal complex in peripheral nociceptors, produces pain relieve $[8,9]$. Thus, it is not surprising that BoNTA is currently used in the clinics for the treatment of chronic inflammatory and neuropathic pain [10-12], thus validating the SNARE complex as a valuable therapeutic target.

Although BoNTA is a potent drug, its therapeutic use is limited because of its high toxicity $[13,14]$. As a therapeutic strategy to circumvent BoNTA toxicity, we previously designed small peptides that mimicked the BoNTA action by destabilizing the assembly of the SNARE complex. Notably, peptide DD04107 (Palmitoyl-EEMQRR-NH 2,1 ) inhibited $\alpha$-CGRP exocytotic release from primary sensory neurons with micromolar potency, and blocked the inflammatory recruitment of transient receptor potential vanilloid type 1 (TRPV1) ion channels to the plasma membrane of nociceptors $[15,16]$. Furthermore, peptides patterned after the $N$-terminal domain of SNAP25 (6-20-mer), a protein component of the SNARE complex, appear to interfere with the SNARE complex formation/stabilization that is essential for $\mathrm{Ca}^{2+}$-dependent exocytosis in excitable cells. As a consequence, DD04107 (1) produced dose-dependent, in vivo analgesic effects in chronic models of inflammatory and neuropathic pain, including inflammation and mechanical hyperalgesia induced by carrageenan, Freund's adjuvant (CFA) and osteosarcoma, and some peripheral neuropathies (chemotherapy, diabetes) [17]. The $\mathrm{N}$-acetyl analogue of DD04107 (Ac-EEMQRR- $\mathrm{NH}_{2}, 2$, Ac-DD04107) is also an inhibitor of neuronal exocytosis, although with a lower potency than BoNTA and DD04107 (1) $[15,18]$. Peculiarly, this peptide is being used as a safe BoNT mimetic by the cosmetic industry for the reduction of expression wrinkles [19], and DD04107 (1) is currently active in phase II clinical trials for neuropathic pain [20].

For $\mathrm{Ca}^{2+}$ exocytosis, the SNARE complex, formed by two domains of SNAP25, synaptobrevin (vesicle-associated membrane protein 2, VAMP2) and syntaxin-1 proteins, interacts with the C2B domain of the $\mathrm{Ca}^{2+}$ sensor synaptotagmin 1 (Syt1) through a primary interface comprising two regions that establish polar interactions, as shown in the 3D structure of pdb code 5KJ7 (Rattus novergicus, Fig. 1) [21]. The first hot-spot involves residues E37, K40, N159, M163 and D166 in the Nand C-domains of the complexed SNAP25 and residues E295, K297, N336 and Y338 of Syt1 [21]. The second region comprises a series of acidic residues of SNAP25 (D51, E52 and E55) and syntaxin-1A (D231, E234 and D238), and a positively charged region in Syt1 (R281, K288, R398 and R399). This second hot-spot was identified by NMR studies as the primary binding mode between Syt-1 and the SNARE complex [22]. In addition, protein SNAP25 needs the interaction with syntaxin-1 to adopt the characteristic head-to-tail structure observed in the SNARE complex, while $N$-terminal truncation of SNAP25 or syntaxin prevented the formation of the ternary complex with VAMP2 [23].

As indicated above, at the first hot-spot, the interaction of Syt 1 with the SNARE complex is largely mediated by contacts with the two domains of SNAP25, with two acidic, a basic, an Asn and a Met residues as key connecting points. These residues, or conservative substitutions, are present in the primary structure of DD04107 (1) and its acetyl derivative

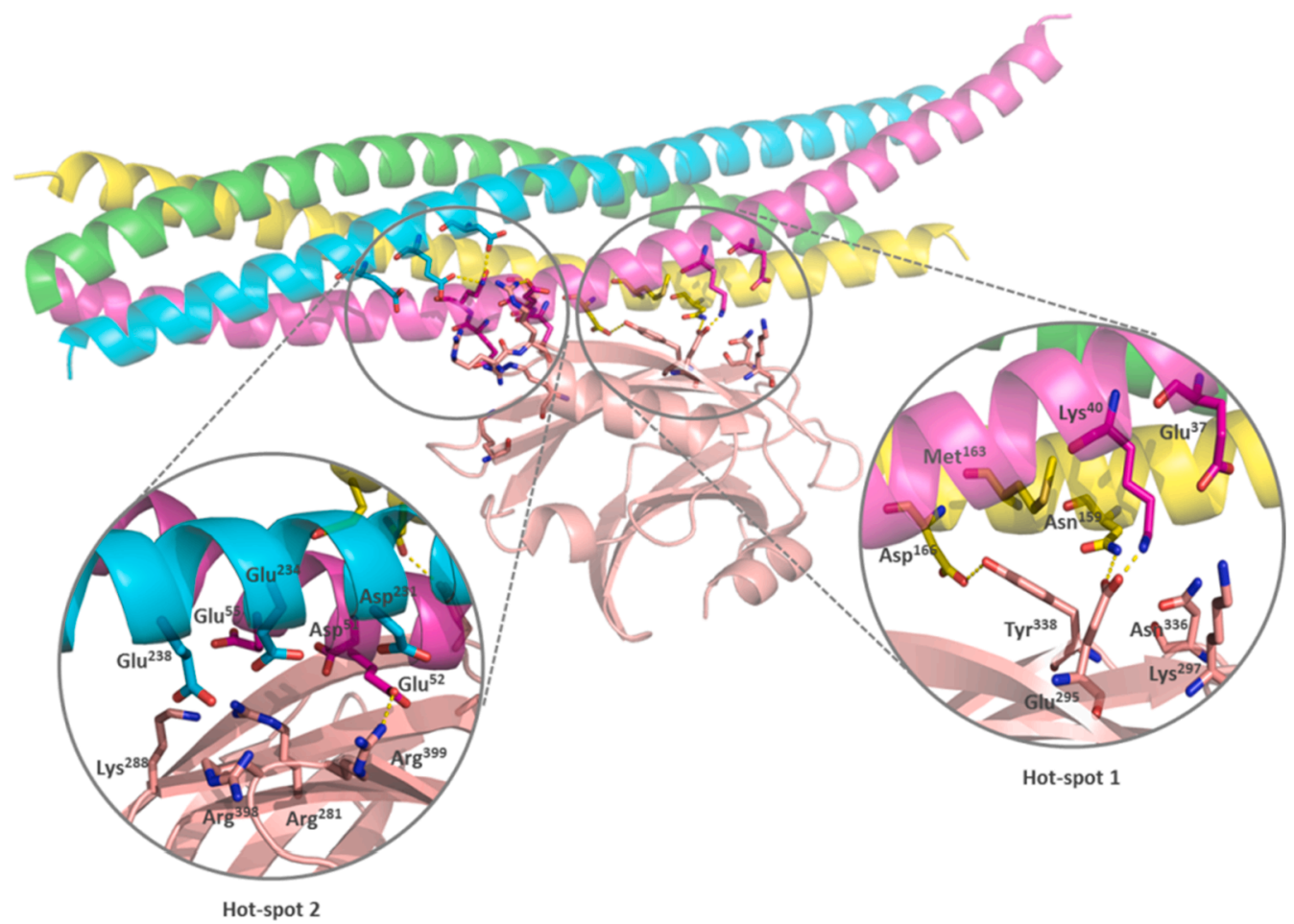

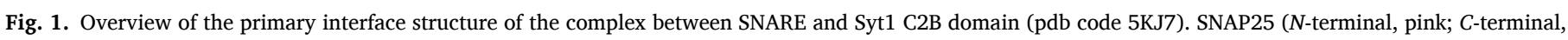

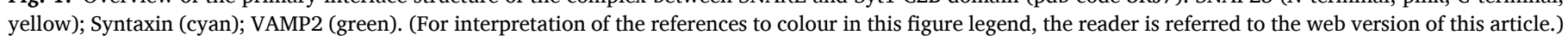


Ac-DD04107 (2). This led us to hypothesize that these peptide derivatives could, at least partially, inhibit neuronal exocytosis by preventing/modifying the interaction of Syt1 with the SNARE complex, by binding to the $\mathrm{Ca}^{2+}$ sensor, and uncoupling/difficulting $\mathrm{Ca}^{2+}$-dependent exocytosis.

To test this hypothesis, herein we investigate Ala mutants and cyclic derivatives of peptide (Ac-DD04107 (2, Fig. 2), in order to uncover the role of individual side-chains on the inhibition of $\alpha$-CGRP release from nociceptors, and for identifying possible bioactive conformations. We use ITC experiments to examine in vitro the interaction of DD04107 (1) and its analogues to Syt1 protein. Finally, we perform induced fit docking (IFD) and molecular dynamic studies to visualize the potential interaction of these peptides with Syt1.

\section{Results and discussion}

\subsection{Peptide synthesis}

Model peptides DD04107 (1) and its acetyl analogue Ac-DD04107 (2) were synthesized manually in parallel on a low load rink amide (MBHA) polystyrene resin. Protecting groups were those normally used in the Fmoc/ ${ }^{t} \mathrm{Bu}$ strategy and peptides were elongated on the resin using HCTU as coupling agent [24]. After incorporation of the last amino acid and Fmoc removal, the resin was splitted in two, palmitoylated and acetylated, respectively, and treated with the cleavage cocktail TFA/ EDT/ $\mathrm{H}_{2} \mathrm{O} / \mathrm{TIS}$ (94:2.5:2.5:1) to afford crude peptides 1 and 2 (Scheme 1). These compounds were finally purified by reverse phase MPLC using $\mathrm{C}_{18}$ SPE cartridges to obtain high purity peptides (>98\%, HPLC), which were characterized by $\mathrm{ESI}^{+}$MS and HRMS.

Following the same procedure, a parallel divergent synthesis was performed to prepare the Ala scan peptides 3-8. These peptides, in which each residue in Ac-DD04107 (2) is individually substituted by Ala, were prepared to shed light on the importance of each side-chain in the biological activity. Acetylated derivatives were selected over palmitoylated analogues because of the easier purification and better solubility in order to facilitate the subsequent conformational studies. To elucidate possible preferred conformations for the bioactivity, we also prepared three cyclic derivatives 9-11, by formation of side-chain amide bonds between residues $1-5,2-5$ and $2-6$, respectively. To this end, the regioselective functionalization of the resin-bound peptides was achieved by incorporation of Fmoc-Glu(OAll)-OH at residues 1 or 2 and Fmoc-Lys(Alloc)-OH at positions 5 or 6 , as required. Allyl and Alloc

\section{Compound}

\begin{tabular}{|c|c|c|c|c|c|c|c|c|}
\hline & & & 1 & 2 & 3 & 4 & 5 & 6 \\
\hline 1 & (DD04107) & Pal- & $E$ & $\mathrm{E}$ & $\mathrm{M}$ & $Q$ & $\mathrm{R}$ & $\mathrm{R}-\mathrm{NH}_{2}$ \\
\hline 2 & (Ac-DD04107) & Ac- & $\mathrm{E}$ & $E$ & $M$ & $\mathrm{Q}$ & $\mathrm{R}$ & $\mathrm{R}-\mathrm{NH}_{2}$ \\
\hline 3 & (R6A-2) & Ac- & $E$ & $E$ & $M$ & $\mathrm{Q}$ & $\mathrm{R}$ & $\mathrm{A}-\mathrm{NH}_{2}$ \\
\hline 4 & (R5A-2) & Ac- & $E$ & $E$ & M & Q & A & $\mathrm{R}-\mathrm{NH}_{2}$ \\
\hline 5 & (Q4A-2) & Ac- & $\mathrm{E}$ & $E$ & M & A & $\mathrm{R}$ & $\mathrm{R}-\mathrm{NH}_{2}$ \\
\hline 6 & (M3A-2) & Ac- & $E$ & $E$ & A & Q & $\mathrm{R}$ & $\mathrm{R}-\mathrm{NH}_{2}$ \\
\hline 7 & $(E 2 A-2)$ & Ac- & $E$ & A & M & Q & $\mathrm{R}$ & $\mathrm{R}-\mathrm{NH}_{2}$ \\
\hline 8 & (E1A-2) & Ac- & A & $\mathrm{E}$ & M & Q & $\mathrm{R}$ & $\mathrm{R}-\mathrm{NH}_{2}$ \\
\hline 9 & $(c 1,5-2)$ & Ac- & $\mathrm{E}$ & $E$ & M & Q & K & $\mathrm{R}-\mathrm{NH}_{2}$ \\
\hline & $(c-2,5-2)$ & Ac- & $E$ & E & $\mathrm{M}$ & $\mathrm{Q}$ & $\begin{array}{l}1 \\
K\end{array}$ & $\mathrm{R}-\mathrm{NH}_{2}$ \\
\hline & $(c 2,6-2)$ & Ac- & $E$ & E & M & $\mathrm{Q}$ & $\mathrm{R}$ & $\mathrm{K}-\mathrm{NH}_{2}$ \\
\hline
\end{tabular}

Fig. 2. Sequences of model peptides 1 (DD04107) and 2 (Ac-DD04107), and new analogues. Changes relative to peptide Ac-DD04107 (2) are highlighted in red. (For interpretation of the references to colour in this figure legend, the reader is referred to the web version of this article.) groups can be orthogonally deprotected with $\left[\mathrm{PhSiH} / \mathrm{Pd}\left(\mathrm{PPh}_{3}\right)_{3}\right.$ to subsequently proceed to the on-resin lactamization using (7-Azabenzotriazol-1-yloxy)trispyrrolidinophosphonium hexafluorophosphate (PyAOP)/1-Hydroxy-7-azabenzotriazole (HOAt) as coupling system, either at room temperature or under microwave irradiation [25].

\subsection{CD and NMR conformational studies}

The conformational behavior of the synthesized peptides was first assessed through circular dichroism (CD). As shown in Fig. 3, model compound Ac-DD04107 (2) shows a characteristic profile of nondefined structure (random coil) in water, while a certain tendency to adopt an $\alpha$-helix-like structure appears in the presence of the structuring solvent trifluoroethanol (TFE, 30\%), with a maximum peak at $\sim 190 \mathrm{~nm}$ and minimum bands at 208 and $222 \mathrm{~nm}$ (Fig. 3). Similar behaviors are observed for Ala derivatives 5-8, but the incorporation of Ala residues at C-terminal positions, as in $\mathbf{3}$ and $\mathbf{4}$, seems to destabilize the secondary structure. As for cyclic peptides, cyclization through 1-5 or 2-6 positions (cyclic peptides 9 and 11, respectively) results in highly structured compounds in $\mathrm{H}_{2} \mathrm{O}$, with typical helix conformations that did not change upon TFE addition (Fig. 3). However, cyclization through $2-5$ positions (cyclic peptide 10), is mainly random coil in both $\mathrm{H}_{2} \mathrm{O}$ and $30 \%$ TFE (Fig. 3).

To get further details into the conformations, we performed a structural NMR study of selected compounds in aqueous solution and in the presence of TFE (30\%). Once assigned the NMR spectra (see Methods), the secondary structure of the peptides was delineated from the conformational shifts (or chemical shift deviations), which are defined as the differences of the observed ${ }^{1} \mathrm{H}_{\alpha},{ }^{13} \mathrm{C}_{\alpha}$, and ${ }^{13} \mathrm{C}_{\beta}$ chemical shifts from the values characteristic of random coil peptides $\left(\Delta \delta_{i}=\delta_{i}{ }^{\text {obs }}\right.$ $\left.-\delta_{\mathrm{i}}^{\mathrm{RC}}, \mathrm{ppm}\right)$. Conformational shifts characteristics of $\alpha$-helices are $\Delta \delta_{\mathrm{H} \alpha}$ $<0, \Delta \delta_{\mathrm{C} \alpha}>0$, and $\Delta \delta_{\mathrm{C} \beta}<0$, and those of extended $\beta$-strands display opposite signs [26-28]. It should be noted that $\left|\Delta \delta_{\mathrm{H \alpha}}\right| \leq 0.05 \mathrm{ppm}$, $\left|\Delta \delta_{\mathrm{C} \alpha}\right| \leq 0.5 \mathrm{ppm}$, and $\left|\Delta \delta_{\mathrm{C} \beta}\right| \leq 0.5 \mathrm{ppm}$ are not significative, because they are within the experimental errors. Ac-DD04107 (2), which was studied as representative of linear peptide derivatives, showed $\Delta \delta_{\mathrm{H} \alpha}$, $\Delta \delta_{C \alpha}$, and $\Delta \delta_{C \beta}$ values indicative of a low populated $\alpha$-helix in equilibrium with random conformations, with the $\alpha$-helix more favored in the presence of $30 \%$ TFE (Figs. $4 \& 5$ ), as indicated by the $\Delta \delta_{\mathrm{H \alpha}}$ (Fig. 4), $\Delta \delta_{\mathrm{C} \alpha}$, and $\Delta \delta_{\mathrm{C} \beta}$ (Fig. 5) conformational shifts being larger in absolute value. The $\Delta \delta / \Delta \mathrm{T}$ values of amide protons provide us additional structural data. Their simplest interpretation is that $|\Delta \delta / \Delta \mathrm{T}|>5 \bullet 10^{-3} \mathrm{ppm}$ corresponds to solvent-exposed amide protons, and that $|\Delta \delta / \Delta \mathrm{T}|<$ $5 \bullet 10^{-3} \mathrm{ppm}$ are likely involved in intramolecular H-bonds $[29,30]$. Thus, the obtained $\Delta \delta / \Delta \mathrm{T}$ values for peptide Ac-DD04107 (2) in aqueous solution (all with absolute values $>4.5 \mathrm{ppb}$; Table 1 ) pointed out that they are totally exposed to the solvent, which is characteristic of peptides without structure or random coil. However, in 30\% TFE, the values for the M3, Q4, R5 and R6 NH protons, whose absolute values are $<4.5 \mathrm{ppb}$, indicated their involvement in intramolecular $\mathrm{H}$-bonds. This is compatible with an $\alpha$-helix, in which the first H-bond would be established between the $\mathrm{CO}$ group of the Ac moiety and the $\mathrm{NH}$ of the $\mathrm{i}+4$ residue (M3). The fact that one of the two protons of the C-terminal amide also have a small $\Delta \delta / \Delta \mathrm{T}$ absolute value (Table 1 ) suggests that this proton might be H-bonded to the $\mathrm{CO}$ group of the $\mathrm{i}+4$ (Q4). The conformational shifts for cyclic peptides $\mathbf{9}$ and $\mathbf{1 1}$ (Figs. 4 and 5), as well as the $\Delta \delta / \Delta \mathrm{T}$ values (Table 1 ) clearly showed that these peptides form $\alpha$-helix structures both in aqueous solution and in $30 \%$ TFE. In contrast, the conformational shifts and the $\Delta \delta / \Delta \mathrm{T}$ values of the cyclic analogue 10 were indicative of a predominantly random coil peptide, both in $\mathrm{H}_{2} \mathrm{O}$ and 30\% TFE (Figs. 4, and 5 and Table 1). The helix populations estimated from the conformational shifts are much greater in $\mathbf{9}$ and $\mathbf{1 1}$ (67-78\%; Table S2) than in Ac-DD04107 (2), either in aqueous solution or in the presence of $30 \%$ TFE $\left(21 \%\right.$ in $\mathrm{H}_{2} \mathrm{O}$ and $28 \%$ in $30 \%$ TFE; Table 2). Those of the cyclic peptide 10 are quite small $\left(15 \%\right.$ in $\mathrm{H}_{2} \mathrm{O}$, and $21 \%$ in $30 \% \mathrm{TFE}$; Table 2). These NMR results are in perfect agreement 


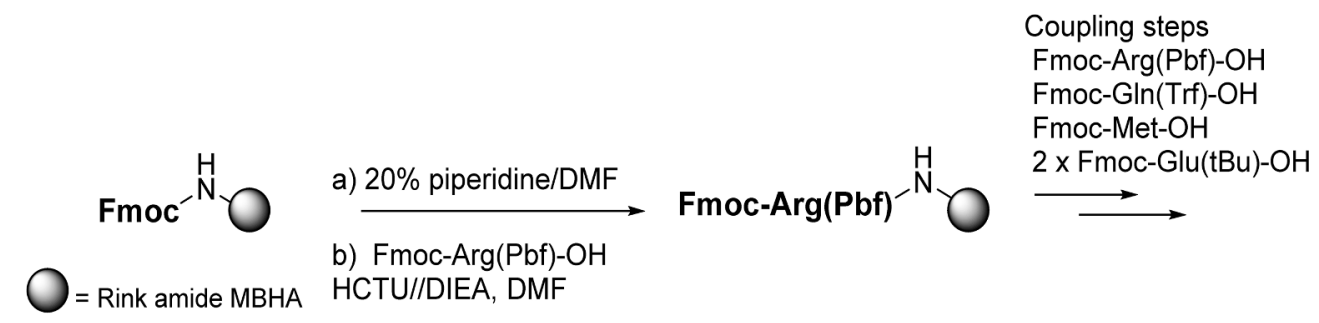

$\longrightarrow$ Fmoc-Glu(tBu)-Glu(tBu)-Met-GIn(Trt)-Arg(Pbf)-Arg(Pbf) ${ }^{\text {N }}$

a) $20 \%$ piperidine/DMF

b) Palmitic acid/HCTU/DIEA or $\mathrm{Ac}_{2} \mathrm{O} / \mathrm{DIEA}$

c) TFA-EDT- $\mathrm{H}_{2} \mathrm{O}-\mathrm{TIPS}$

$(94: 2.5: 2.5: 1)$<smiles>[R]N[C@@H](CCC(=O)O)C(=O)N[C@@H](CCC(=O)O)C(=O)N[C@@H](CCSC)C(=O)N[C@@H](CCC(N)=O)C(=O)N[C@@H](CCCNC(=N)N)C(=O)N[C@@H](CCCNC(=N)N)C(N)=O</smiles>

Scheme 1. General strategy for the solid-phase synthesis.

with those of CD. Thus, as reported in other peptide systems [31], the $\mathrm{i}, \mathrm{i}$ +4 cyclization is helix-stabilizing, but not the $i, i+3$.

Apart from conformational shifts and $\Delta \delta / \Delta T$ values, the set of NOEs provide the strongest evidence about structure formation in peptides $[26,33]$. Thus, the non-sequential NOEs, which are $\alpha \mathrm{N}(\mathrm{i}, \mathrm{i}+3), \alpha \mathrm{N}(\mathrm{i}, \mathrm{i}+$ 4), and/or $\alpha \beta(i, i+3)$, observed for peptide Ac-DD04107 (2) and for the cyclic peptides $\mathbf{9}$ and $\mathbf{1 1}$ demonstrated that they form $\alpha$-helical structures (Figure S1, SM). These non-sequential NOEs are intense in $\mathbf{9}$ and 11, and weak in 2, which is in agreement with the helix being less populated in the linear peptide Ac-DD04107 (2). No non-sequential NOE was observed in the case of $\mathbf{1 0}$ (Figure S1, SM), which provides further confirmation of this peptide being mainly random coil. More interestingly, the features of the helices formed by peptides 2,9 and 11 can be visualized by performing structure calculations based on the distance constraints derived from the observed sets of NOEs (see Methods). Structure calculation was not performed for the cyclic peptide 10, because of its very low helix population and the absence of nonsequential NOEs in both $\mathrm{H}_{2} \mathrm{O}$ and $30 \%$ TFE. The resulting structures for peptides 2, 9 and $\mathbf{1 1}$ are well-defined helices (see Figure S2 and Table S9, SM). It is interesting to notice that in the helix formed by AcDD04107 (2) E1 and R5 sidechains, as well as E2 and R6 sidechains are spatially close, which explains that peptides 9 and 11, with the 1-5 and 2-6 bridges, form quite stable helices (Table 2). However, E2 and R5 sidechains are not close in the peptide 2 's helix (Figure S2, SM), so it seems reasonable that the formation of a 2-5 bridge has to lead to a somehow distorted helix. This agrees with our experimental finding about peptide 10, with the $2-5$ bridge, being less helical than the linear peptide (see Table 2).

\subsection{Biological activity examined by inhibition of $\alpha$-CGRP release}

To test the importance of Ala substitutions and cyclization, all compounds were assayed for their ability to inhibit in vitro $\alpha$-CGRP release from rodent nociceptors (Table 3). In this assay, compounds DD04107 (1) at $10 \mu \mathrm{M}$ and Ac-DD04107 (2) at $100 \mu \mathrm{M}$ inhibited capsaicin-induced release of $\alpha$-CGRP by approximately $45 \%$. A significant inhibition at $100 \mu \mathrm{M}(\approx 30 \%)$ was also obtained for peptide derivatives 4 and 7, with R5A and E2A mutations, thus indicating that E2 and $\mathrm{R} 5$ residues are not crucial for the activity. In contrast, mutation of the other four residues afforded Ala derivatives with highly reduced (3 and 5) or total loss (6 and 8) of the inhibitory activity. These results indicate that within this series of peptides side-chains of Q4 and R6, and especially E1 and M3, are pivotal for inhibiting neuronal exocytosis. In good accordance, masking one of these important side-chains through cyclization, as E1 in cyclic peptide 9 and R6 in cyclic analogue 11, resulted in a drastic reduction of the inhibitory properties compared to the corresponding linear analogue Ac-DD04107 (2). On the contrary, cyclization through the two unimportant residues, at positions 2 and 5 , led to cyclic peptide $\mathbf{1 0}$ that recovers the inhibitory properties of the linear model compound. The fact that $\mathbf{1 0}$ is mainly random-coil in solution seems to suggest that the helical conformation observed for model compound Ac-DD04107 (2) in the presence of the membrane-like environment of TFE is not required for the inhibitory activity of these peptides. 

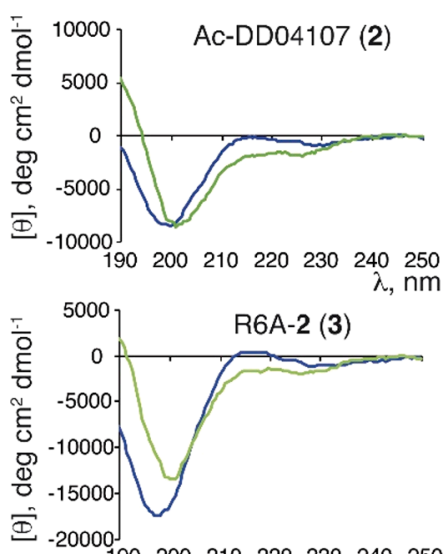

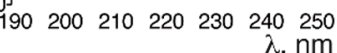

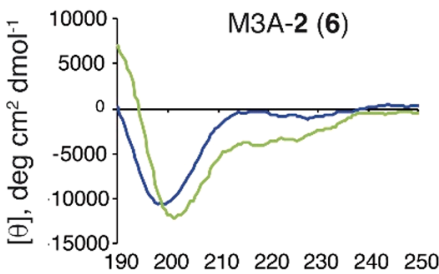

$190 \quad 200210220230240250$

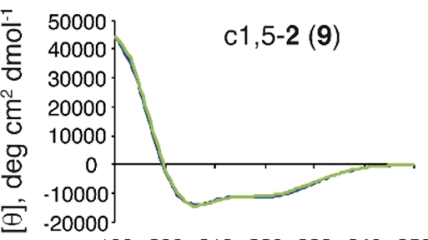

$190 \quad 200210220230240250$
$\lambda, \mathrm{nm}$

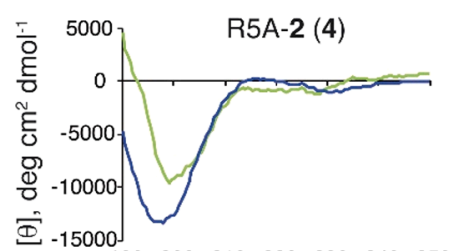

$\begin{array}{llllll}190 & 200 \quad 210 & 220 & 230 & 240 & 250\end{array}$

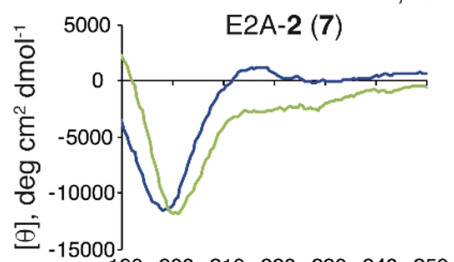

$\lambda, \mathrm{nm}$

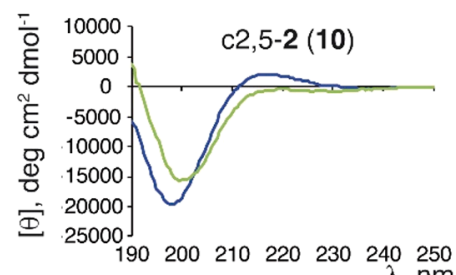

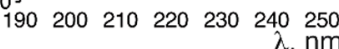
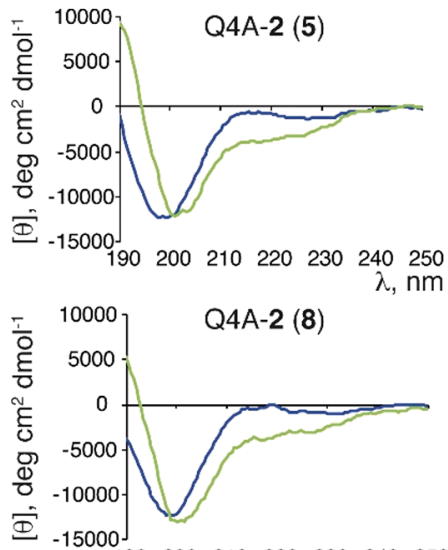

190200210220230240250

$\lambda, \mathrm{nm}$

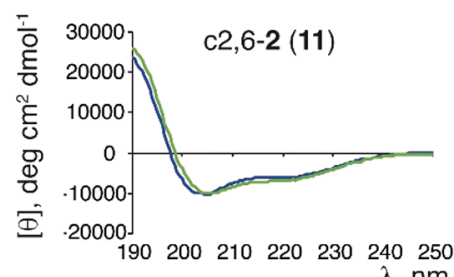

$\lambda, \mathrm{nm}$

Fig. 3. CD spectra of peptides 2-11 in aqueous solution (blue line) and in $30 \%$ TFE (green line) at $\mathrm{pH} 5.5$ and $5{ }^{\circ} \mathrm{C}$. (For interpretation of the references to colour in this figure legend, the reader is referred to the web version of this article.)
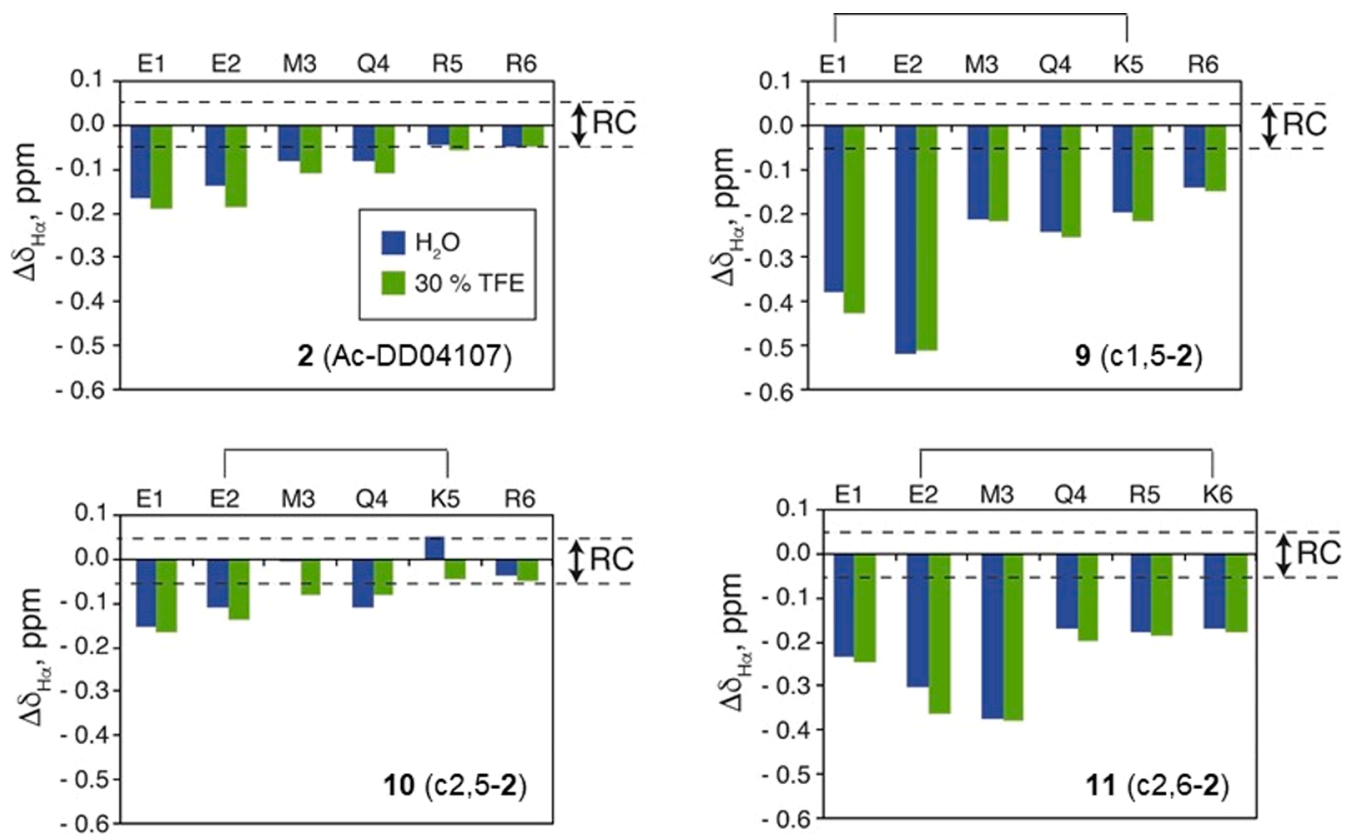

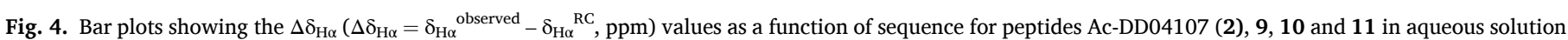

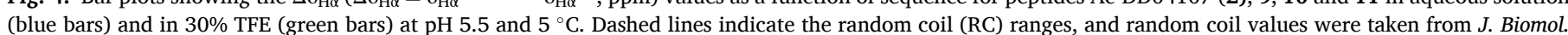
NMR 1995, 5, 67-81 [32]. (For interpretation of the references to colour in this figure legend, the reader is referred to the web version of this article.) 

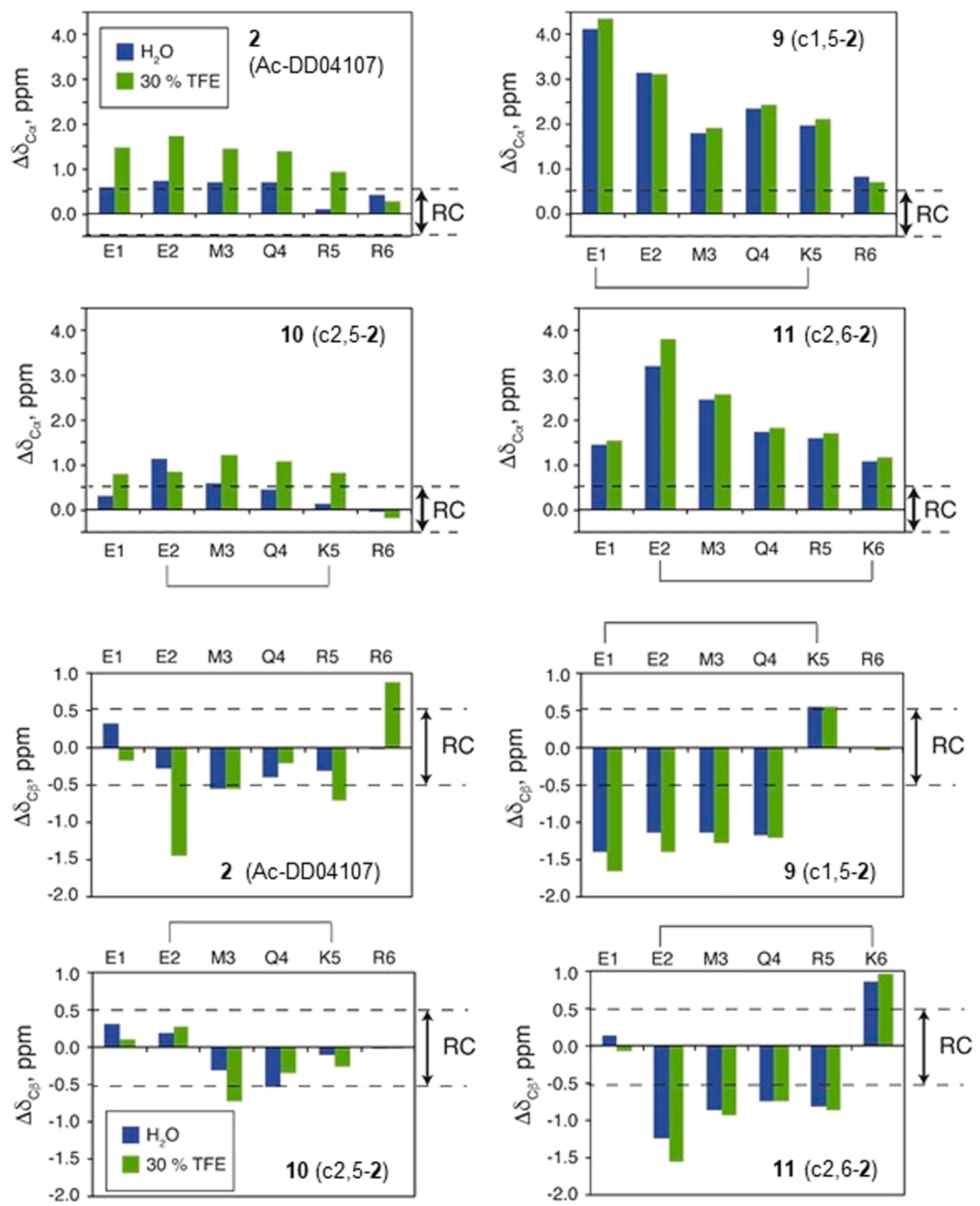

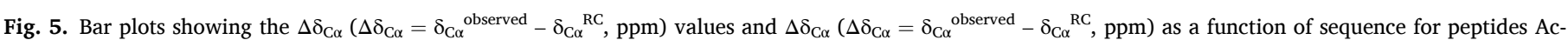

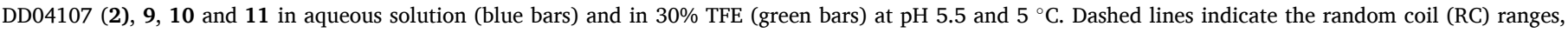

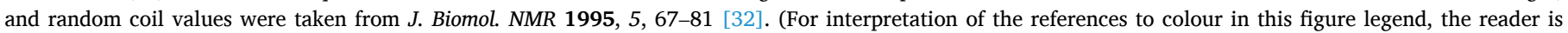
referred to the web version of this article.)

\subsection{Isothermal titration calorimetry (ITC): Syt1-CB2 binding ability and specificity}

Next, we addressed the hypothesis of a direct interaction of these peptides with Syt 1 that could underlie their inhibitory activity. For this purpose, we recombinantly expressed and purified the C2B domain of Syt1 (Syt1-C2B domain) and used ITC as a methodology that directly and sensitively measures ligand-protein interaction, and allows to determine the equilibrium constant $\left(\mathrm{K}_{\mathrm{D}}\right)$ (Table 3, Fig. 6). Analysis of the
ITC data indicated that DD04107 (1) and its acetyl analogue AcDD04107 (2) are able to bind to the Syt1-C2B domain with an identical $\mathrm{K}_{\mathrm{D}}$ value (i.e. $2.4 \mu \mathrm{M}$ ), suggesting that the fatty acid chain does not directly participate in the interaction with the protein.

The interaction of linear and cyclic analogues of Ac-DD04107 (2) with Syt1 was also investigated by ITC (Table 3, Fig. 6). As shown, most of these peptides bind the purified Syt1-C2B domain protein, and reveal an overall positive correlation between the percentage of $\alpha$-CGRP inhibition and the $\mathrm{K}_{\mathrm{D}}$. With the exception of peptide $4, \mathrm{~K}_{\mathrm{D}}$ values higher than 
Table 1

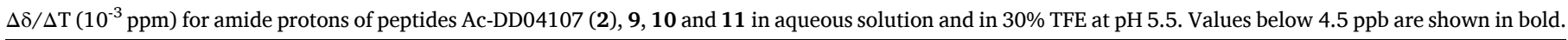

\begin{tabular}{|c|c|c|c|c|c|c|c|c|}
\hline \multirow[t]{2}{*}{ Residue } & \multicolumn{2}{|c|}{2 (Ac-DD04107) } & \multicolumn{2}{|l|}{$9(\mathrm{c} 1,5-2)$} & \multicolumn{2}{|l|}{$10(\mathrm{c} 2,5-2)$} & \multicolumn{2}{|l|}{$11(\mathrm{c} 2,6-2)$} \\
\hline & $\mathrm{H}_{2} \mathrm{O}$ & $30 \% \mathrm{TFE}$ & $\mathrm{H}_{2} \mathrm{O}$ & $30 \% \mathrm{TFE}$ & $\mathrm{H}_{2} \mathrm{O}$ & $30 \% \mathrm{TFE}$ & $\mathrm{H}_{2} \mathrm{O}$ & $30 \%$ TFE \\
\hline E 1 & -6.9 & -6.4 & -7.8 & -8.5 & -6.4 & -5.6 & -7.6 & -7.7 \\
\hline E 2 & -5.9 & -4.7 & -8.5 & -0.9 & -6.6 & -6.2 & -6.4 & -6.9 \\
\hline M 3 & -6.4 & -3.0 & -4.2 & -3.3 & -7.3 & -5.5 & -1.9 & -1.4 \\
\hline Q 4 & -6.0 & -2.8 & -3.1 & -2.6 & -6.6 & -4.9 & -4.4 & -3.3 \\
\hline $\mathrm{R} / \mathrm{K} 5$ & -7.3 & -4.0 & -2.4 & -2.9 & -9.6 & -7.7 & -3.3 & -4.4 \\
\hline $\mathrm{R} / \mathrm{K} 6$ & -7.2 & -3.1 & +1.1 & -0.9 & -9.3 & -8.6 & -0.4 & -1.0 \\
\hline $\mathrm{CONH}_{2}$ & $-6.1,-5.3$ & $-5.7,-2.8$ & $-6.9,+0.5$ & $-7.9,-0.6$ & $-6.2,-6.6$ & $-6.4,-6.0$ & $-7.8,+0.6$ & $-7.0,-0.3$ \\
\hline
\end{tabular}

Table 2

Estimated helix populations for peptides Ac-DD04107 (2), 9, 10 and 11 in aqueous solution and in $30 \%$ TFE at pH 5.5 and $5{ }^{\circ} \mathrm{C}$.

\begin{tabular}{|c|c|c|c|c|c|c|}
\hline Peptide & Conditions & Averaged $\Delta \delta_{\mathrm{H} \alpha}, \mathrm{ppm}$ & $\%$ helix from $\Delta \delta_{\mathrm{H} \alpha}$ & Averaged $\Delta \delta_{\mathrm{C} \alpha}, \mathrm{ppm}$ & $\%$ helix from $\Delta \delta_{\mathrm{C} \alpha}$ & Averaged \% helix \\
\hline \multirow[t]{2}{*}{ 2(Ac-DD04107) } & $\mathrm{H}_{2} \mathrm{O}$ & -0.09 & 24 & 0.54 & 18 & $21 \pm 2$ \\
\hline & $30 \%$ TFE & -0.12 & 30 & 1.21 & 25 & $28 \pm 2$ \\
\hline \multirow{2}{*}{$9(\mathrm{c} 1,5-2)$} & $\mathrm{H}_{2} \mathrm{O}$ & -0.28 & 61 & 2.37 & 77 & $69 \pm 5$ \\
\hline & $30 \%$ TFE & -0.30 & 76 & 2.44 & 79 & $78 \pm 1$ \\
\hline \multirow[t]{2}{*}{$10(\mathrm{c} 2,5-2)$} & $\mathrm{H}_{2} \mathrm{O}$ & -0.06 & 15 & 0.43 & 14 & $15 \pm 0$ \\
\hline & $30 \%$ TFE & -0.06 & 16 & 0.77 & 25 & $21 \pm 3$ \\
\hline \multirow[t]{2}{*}{$11(\mathrm{c} 2,6-2)$} & $\mathrm{H}_{2} \mathrm{O}$ & -0.24 & 72 & 1.93 & 62 & $67 \pm 3$ \\
\hline & $30 \%$ TFE & -0.26 & 66 & 2.11 & 68 & $67 \pm 1$ \\
\hline
\end{tabular}

Table 3

Biological activity and Syt1-CB2 binding of DD04107 (1) and analogues.

\begin{tabular}{|c|c|c|c|}
\hline Compd. & Formula & $\begin{array}{l}\text { Inhibition CGRP } \\
(\%)\end{array}$ & $\begin{array}{l}\text { ITC (Syt1) } K_{D} \\
(\mu \mathrm{M})\end{array}$ \\
\hline 1(DD04107) & $\begin{array}{l}\text { Pal-E }{ }^{1} E^{2} M^{3} Q^{4} R^{5} R^{6} \text { - } \\
\mathrm{NH}_{2}\end{array}$ & $47.0 \pm 20$ & $2.4 \pm 0.6$ \\
\hline $\begin{array}{l}\text { 2(Ac- } \\
\quad \text { DD04107) }\end{array}$ & Ac-EEMQRR-NH ${ }_{2}$ & $44.6 \pm 10.3$ & $2.4 \pm 0.5$ \\
\hline 3 (R6A-2) & Ac-EEMQRA-NH ${ }_{2}$ & $3.8 \pm 3.8$ & $5.2 \pm 0.9$ \\
\hline 4(R5A-2) & Ac-EEMQAR-NH ${ }_{2}$ & $27.0 \pm 1.2$ & $8.0 \pm 2.0$ \\
\hline 5(Q4A-2) & Ac-EEMARR- $\mathrm{NH}_{2}$ & $4.9 \pm 4.9$ & $\mathrm{NI}^{\mathrm{a}}$ \\
\hline 6(M3A-2) & Ac-EEAQRR-NH ${ }_{2}$ & 0.0 & $\mathrm{NI}^{\mathrm{a}}$ \\
\hline $7(\mathrm{E} 2 \mathrm{~A}-2)$ & Ac-EAMQRR-NH ${ }_{2}$ & $31.6 \pm 1.4$ & $4.2 \pm 0.7$ \\
\hline 8(E1A-2) & Ac-AEMQRR-NH ${ }_{2}$ & 0.0 & $5.8 \pm 0.8$ \\
\hline $9(\mathrm{c} 1,5-2)$ & $\begin{array}{l}\text { Ac-cyclo }[E E M Q K] \mathrm{R}- \\
\mathrm{NH}_{2}\end{array}$ & $1.8 \pm 1.8$ & $10.0 \pm 3.0$ \\
\hline $10(c 2,5-2)$ & $\begin{array}{l}\text { Ac-E-cyclo }[E M Q K] \text { R- } \\
\mathrm{NH}_{2}\end{array}$ & $51.3 \pm 1.9$ & $3.5 \pm 0.5$ \\
\hline $11(c 2,6-2)$ & $\begin{array}{l}\text { Ac-E-cyclo[EMQRK]- } \\
\mathrm{NH}_{2}\end{array}$ & $5 \pm 1.9$ & $6.0 \pm 0.9$ \\
\hline $12(\mathrm{c} 2,5-1)$ & $\begin{array}{l}\text { Pal-E-cyclo }[E M Q K] \mathrm{R}- \\
\mathrm{NH}_{2}\end{array}$ & $45 \pm 29.7$ & $\mathrm{ND}^{\mathrm{b}}$ \\
\hline
\end{tabular}

a NI: No interaction observed.

b Not determined because this peptide precipitates in the buffer used for ITC experiments. $\mathrm{Pal}=$ Palmitoyl.

$5.0 \mu \mathrm{M}$ resulted in lack of exocytosis inhibition $(<5 \%)$.

Peptides 5 and $\mathbf{6}$ do not show interaction with Syt1-C2B domain, thus validating a key role of M3 and Q4 residues for the biological activity of DD04107 (1). The $K_{D}$ values for peptides 3 and 4 are lower than those of DD04107 (1) and Ac-DD04107 (2), indicating a role of R6 and R5 residues in the binding with the protein, more important for R5 (compound 4). However, this do not correlate with the ability of these peptides to inhibit $\alpha$-CGRP release, with peptide 4 showing better activity than 3 . The inactivity of compound 3 cannot be attributed solely to the $\mathrm{K}_{\mathrm{D}}$ value of $5.2 \mu \mathrm{M}$, which is lower than that of 4 , but to other parameters such as a different cell penetration or an inappropriate positioning of crucial side-chains, like those of residues M3 and Q4. Similarly, both E-to-A mutants 7 and 8 are able to bind the Syt1-C2B domain, although compound 8 , which shows a higher $\mathrm{K}_{\mathrm{D}}$ value $(5.8 \mu \mathrm{M})$, fails to inhibit $\alpha$-CGRP exocytotic release (Table 3 ). As for compound $\mathbf{3}$, the inactivity of compound $\mathbf{8}$ in the cellular assay could be related to lower membrane permeability. All cyclic peptides are able to bind to Syt1-C2B domain, with the best $\mathrm{K}_{\mathrm{D}}$ value for the 2-5-cyclic peptide 10 , which also displays the most potent inhibitory activity, thus substantiating that residues 2 and 5 are not crucial neither for Syt1-C2B binding nor for inhibiting $\alpha$-CGRP release. As shown in Fig. 6, tritration injections of cyclic peptide 10 are similar to those of linear model peptide Ac-DD04107 (2), while for regioisomeric cyclic analogues $\mathbf{9}$ and $\mathbf{1 1}$ the interaction is visibly weaker. The affinity values of cyclic peptides $\mathbf{9}$ (cyclo-1-5) and $\mathbf{1 1}$ (cyclo 2-6) correlate quite well with those of the corresponding linear analogues 4 and 3, with Ala residues at positions 5 and 6, respectively. However, considering that $\mathbf{9}$ and $\mathbf{1 1}$ are stable $\alpha$-helical peptides while 10 displays a random coil conformation in solution, the low activity of 9 and $\mathbf{1 1}$ in the cellular assay is plausibly due to the lack of residues E1 and R6, respectively, along with a possible inappropriate three-dimensional disposition of residues M3 and Q4, forced by the $\alpha$-helical structure.

Next, we explored the specificity for Syt1-C2B domain through ITC experiments with Syt7-C2B, which was selected as representative of Syt proteins non homologous with Syt1 in the region that accommodate the first hot-spot (Figure S3, SM). Thus, the pattern of E295, K297, N336 and Y338 of Syt1-C2B ${ }^{15}$ is only repeated in Syt2, Syt5, and Syt8 (Figure S3, $\mathrm{SM}$ ), while became $\mathrm{K}, \mathrm{R}, \mathrm{N}, \mathrm{I}$, respectively, in Syt7-C2B, with the $\mathrm{K}$ residue present in most other C2B domains of Syt proteins. The ITC experiments demonstrated that none of our peptides were able to bind to recombinantly expressed and purified Syt7-C2B, thus supporting that the indicated region of the Syt1-C2B domain is most likely the interacting partner of DD04107 (1) and its analogues.

\subsection{Attenuation of thermal hyperalgesia}

CFA-induced inflammatory pain model has been widely used for describing the effectiveness of different types of analgesics. In this experimental model, the intraplantar (i.pl.) administration of Freund's adjuvant (CFA) provoked a marked thermal hyperalgesia, indicated by the important decreased latency to a heat source, while no effects were observed in the contralateral paw. For central acting analgesics, there are controversial reports on their effectiveness in inflammatory pain states [34,35], and the antinociceptive effect of morphine against thermal hyperalgesia seems to follow a different mechanism from that of mechanical allodynia [36]. The effect of NSAIDs, like ibuprofen, on inflammatory hyperalgesia is mediated either by the cyclooxygenase pathway and up-regulation of Nav1.7 and 1.8 ion channels [37].

As indicated above, peptide DD04107 (1) is an inhibitor of the CGRP 

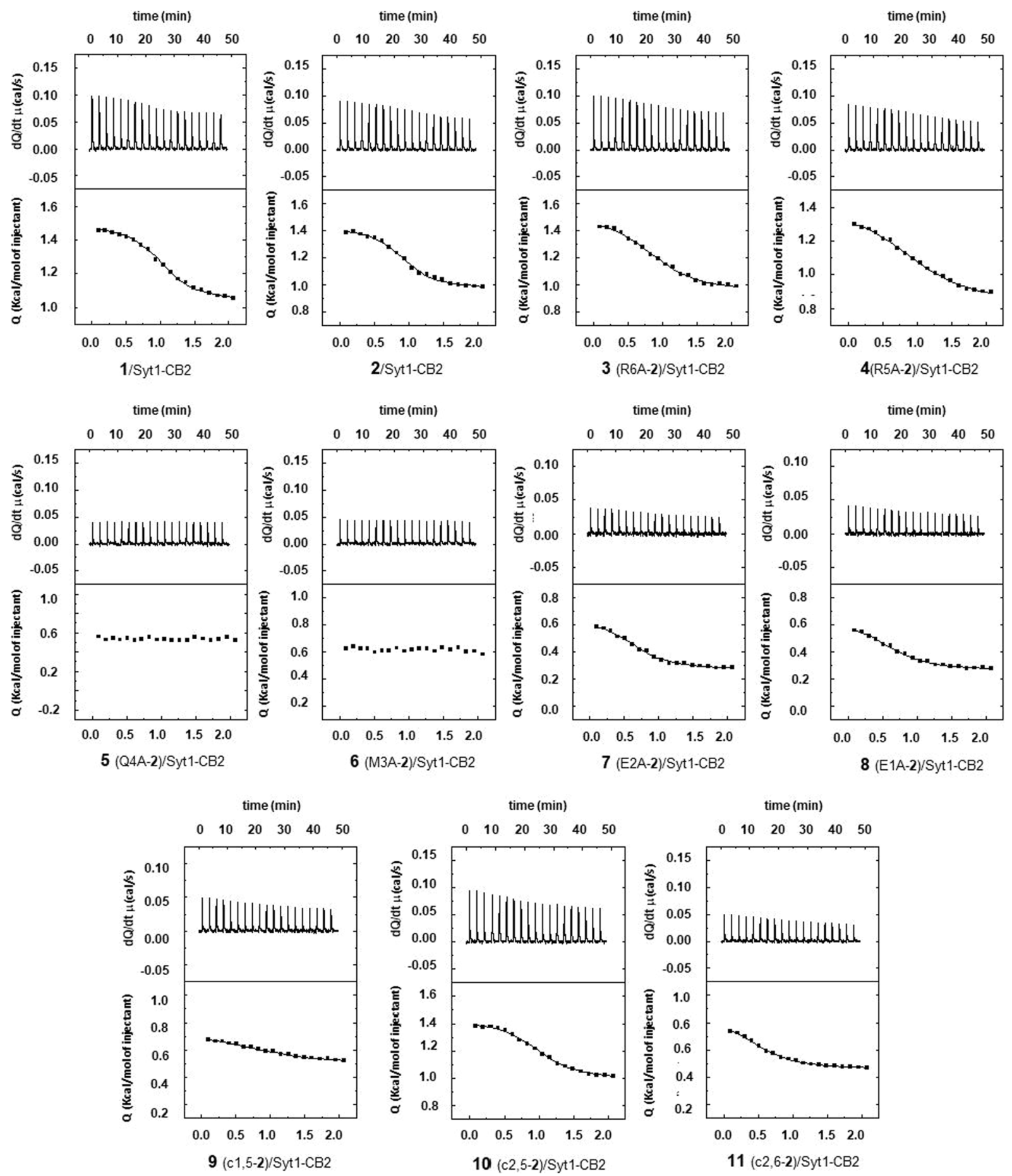

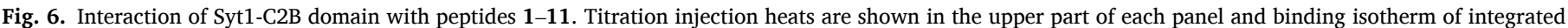
binding enthalpies in the lower part of each panel. $K_{D}$ values are shown in Table 1.

release that shows analgesic activity in different models of inflammatory and neuropathic pain. ${ }^{15}$ Thus, DD04107 (1) mitigated the inflammation and mechanical hyperalgesia induced by carrageenan, showing antiinflammatory activity similar to ciclofenac. This peptide derivative also attenuated thermal hyperalgesia and mechanical allodynia induced either by CFA or osteosarcoma, decreased mechanical hyperalgesia induced by vincristine and paclitaxel chemotherapeutic agents, and ameliorated diabetic neuropathy. More importantly, DD04107 (1) did not act on opioid receptors, neither displayed blockade of hERG currents at therapeutic doses, showing a safe profile. It was also described that the non-palmitoylated peptide displayed lower pain attenuation, most probably due to a reduced permeability. ${ }^{15}$ Since cyclic peptide 10 showed good inhibitory neuronal exocytosis, slightly higher than its linear analogue 2 , we were interested in evaluating the antinociceptive activity of the corresponding palmitoylated analogue. To this end, we prepare cyclic peptide Pal-E-cyclo[EMQK]R- $\mathrm{NH}_{2}$ (12), cyclic analogue of DD04107 (1) and palmitoylated analogue of cyclic peptide derivative 10. Peptide 12 shows similar inhibition of CGRP release, compared to model peptide 1 . The in vivo analgesic activity of peptide 12 was measured in the indicated model of CFA-induced inflammatory pain in mice. Injection of cyclic peptide 12 ( $1 \mu$ g, i.pl.) in the ipsilateral paw induces a fast, significant increase of the thermal latencies, still 
important after $2 \mathrm{~h}$, compared to vehicle-treated animals. In addition, peptide 12 did not modify thermal latencies in the non-inflamed left paw of treated animals (Fig. 7). These results indicate that peptide 12, a cyclic analogue of DD04107 (1), displays local anti-hyperalgesic activity against inflammatory pain. Compared to DD04107 (1), peptide 12 showed faster analgesic activity, probably due to the local administration, and similar duration. To the best of our knowledge, the involvement of Syt-1 in inflammatory pain has never been described, but a recent paper correlates the expression of Syt-1 to neuropathic pain and its attenuation by electroacupuncture [38].

\subsection{A model for peptide/Sy1-CB2 interaction}

To get insight into the binding mode of this family of peptides to Syt1, induce fit docking (IFD) studies were carried out by the Schrodinger suite of programs [39-44], using model compound Ac-DD04107 (2) and the Syt1-C2B domain from the structure of Syt1-SNARE complex (pdb code 5KJ7) [45]. Based on our initial hypothesis, and on the fact that Ac-DD04107 (2) is able to bind to Syt1 and not to Syt7, we selected Syt1 residues E336, K297, D366 and Y338 (first hot-spot) as part of the binding site. This site is different from that recently suggested from an exclusively theoretical study (10 ns MD simulation), in which peptide 2 bound in a cleft between the C2A-C2B interface [46]. However, our ITC studies demonstrated experimentally that Ac-DD04107 (2) is able to bind to the C2B domain alone. Our IFD results were analyzed to select those poses that fulfil the experimental requirements deduced from the Ala scan on peptide Ac-DD04107 (2). The selected poses were then submitted to molecular dynamic (MD) simulations in a TIP3P water box, using Amber program $[47,48]$. MD studies showed that Ac-DD04107 (2) binding site is overlapping with that of the first hot-spot of SNARE-Syt-1 interface. Ac-DD04107 (2) is bounded to Syt-1 through a network of polar interactions and hydrophobic contributions (Fig. 8). Thus, the $\alpha-\mathrm{NH}$ protons of E2 and Q4 act as H-bond donors to Syt1 A402 (CO) and E295 (sidechain CO), respectively, whereas the acetyl CO group forms a H-bond with the backbone NH of W404. These three H-bonds, and the electrostatic interaction between the R6 guanidinium group and the side-chain $\mathrm{CO}_{2} \mathrm{H}$ group of Syt1 D275, have occupancies over $90 \%$ along the simulation (Figures S4, S5, SM). Other H-bonds (around 50-60\% occupancy) are the indol NH of Syt1 W404 and backbone COs of E2 and Q4, and the side-chain $\mathrm{NH}_{2}$ of Q4 and the side-chain CO of Sty1 E295. These polar interactions are in agreement with our Ala scan studies, in which the mutation of R6 and Q4 to A in peptide $\mathbf{2}$ (derivatives $\mathbf{3}$ and $\mathbf{5}$, respectively) led to a considerable decrease in the $K_{D}$ values (Table 1). There is also hydrophobic contributions to the binding, since M3 in AcDD04107 (2) is surrounded by Syt1 residues C277, L294, and the hydrophobic part of E295, Y338 and W404. Interestingly, peptide AcDD04107 (2) is not able to bind to Syt7, in which E295 and Y338 have been replaced by K and I, respectively. The binding pocket of M3, and more importantly the H-bonds between both backbone and sidechain $\mathrm{NH}$ of Q4 and Syt1 $\mathrm{CO}_{2}$ group of E295, might explain the lack of interaction with Syt7. It is worth to mention that E295 in the complex with SNAP25 (pdb code 5KJ7) establishes H-bonds with K40 and N159 (Fig. 1) [21]. In the binding site, peptide conformation is stabilized by a series of intramolecular H-bonds, mainly between R5 and E1. However, the 3D disposition does not correspond to a regular secondary peptide structure, in agreement with the good ITC binding of the non-structured cyclic peptide 10. The guanidinium moiety of R5 is involved in H-bonds with the backbone CO group of E1 (61\% occupancy, Figure S6, SM). Additionally, R5 guanidinium is also salt-bridged with the side-chain CO of E1 (35\%). The stabilizing role of R5 might account for the decrease in affinity of peptide 4 , in which this residue has been mutated to A.

Based on this MD model and the observed selectivity for Syt1 over Syt7, it is expected that Ac-DD04107 (2) could bind preferentially to only four out of seventeen members of the Syt family. The sequence alignment of the seventeen Syt proteins (Figure S3, SM) shows that just Syt 1, 2, 5 and 8 have a glutamic acid residue at the Syt1 E295 equivalent position, while other members have a basic residue. In addition, only the above mentioned four Syt proteins have $\mathrm{C}$ and $\mathrm{Y}$ residues at the corresponding positions in Syt1 (C277 and Y338). This means that key residues M3 and Q4, situated at the middle of the peptide sequence, are not only important for Syt1 affinity, but also for selectivity.

\section{Conclusions}

Peptide DD04107 (1) inhibits $\alpha$-CGRP exocytotic release and displays interesting analgesic properties, probably through interference with the SNARE complex formation. After the publication of the SNARESyt1 complex and the identification of the main hot-spots on the interaction surface, we hypothesized that DD04107 (1) and its acetyl analogue Ac-DD04107 (2) could interfere in the formation of this complex through the interaction with Syt1. First, we performed an Ala scan on peptide Ac-DD04107 (2) to explore the role of the individual side-chains in the inhibition of $\alpha$-CGRP release (peptides 3-8), and study the conformational behaviour of these linear peptides and some cyclic analogues (9-11) to get insight into the bioactive conformation. From these studies, we learn that E1, M3, Q4 and R6 side-chains are important for the activity, while the tendency to adopt helical conformation could not be correlated neither with the potency to inhibit $\alpha$-CGRP exocytotic release nor with the $\mathrm{K}_{\mathrm{D}}$ value for the interaction with Syt1. ITC experiments with this series of linear and cyclic peptides allowed us to prove

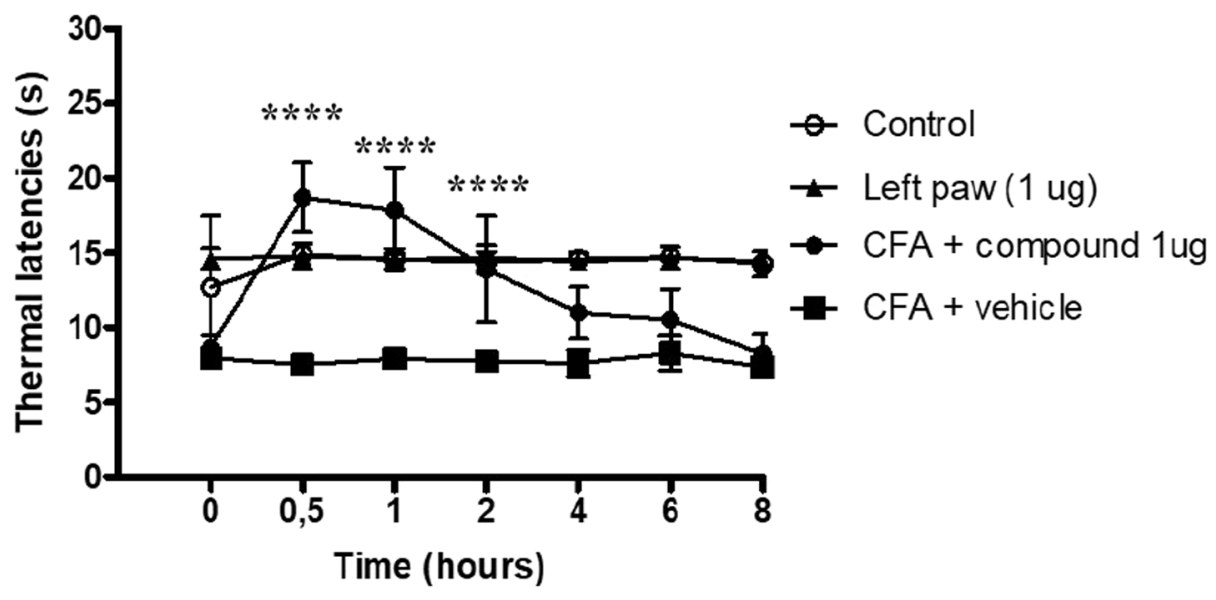

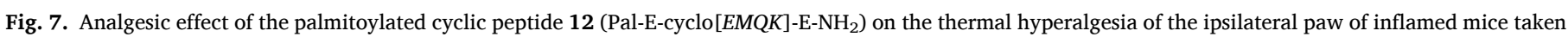

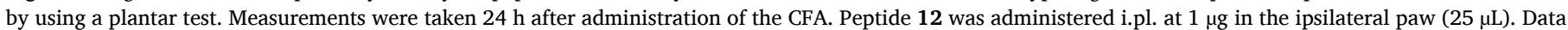

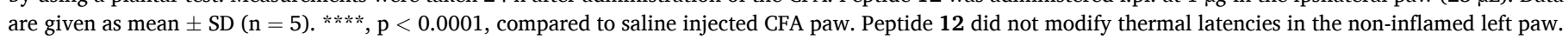




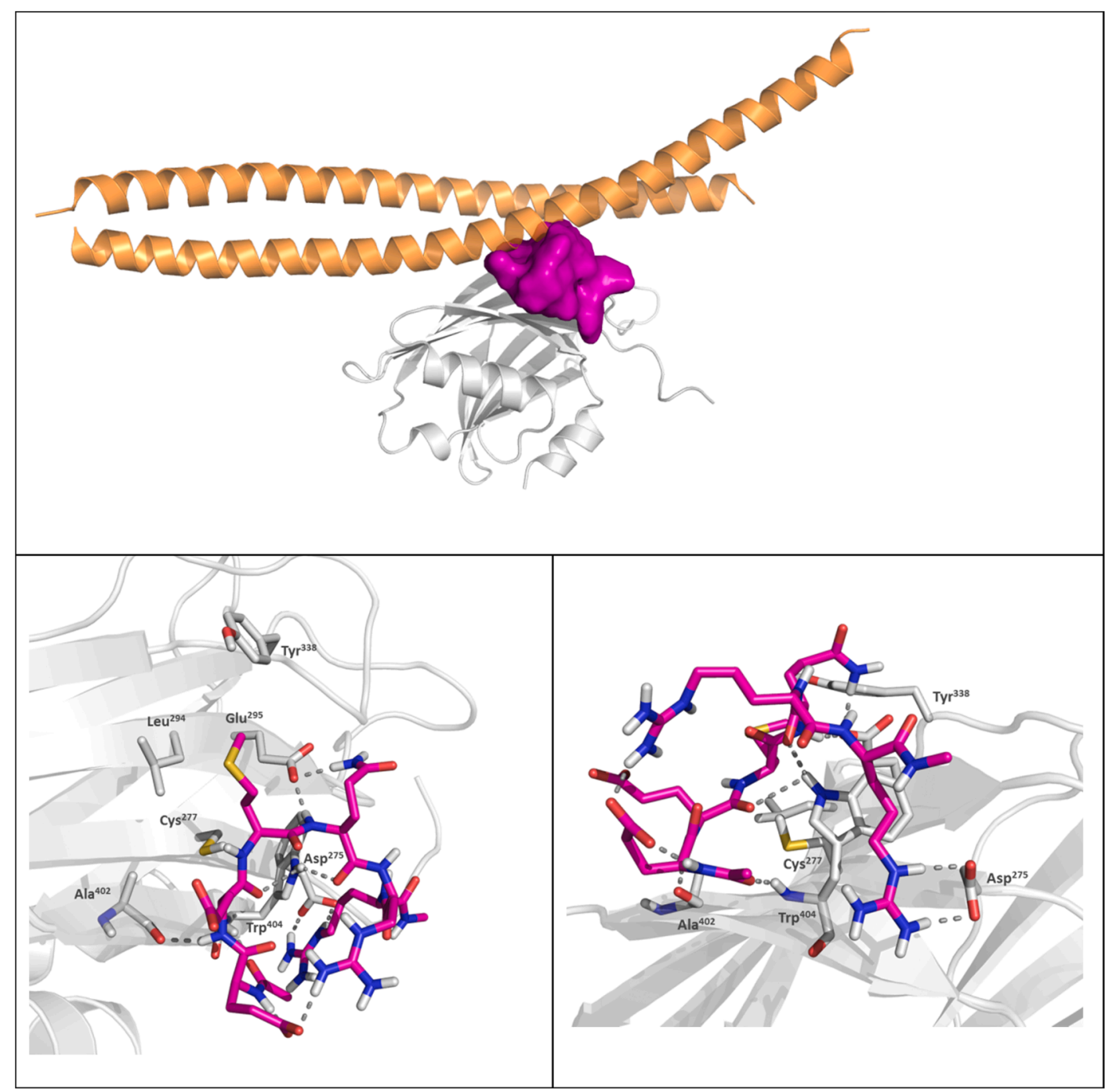

Fig. 8. Upper panel. Superposition of the docking model of Syt1 (white) bound to peptide Ac-DD04107 (2) (pink) with the SNAP25 protein (orange, pdb code 5KJ7 [30]; this pdb structure encompass SNAP25 and Syt1, among other proteins). Lower panels: Close views of the docking model of Syt1 (white)-peptide Ac-DD04107 (2), pink) complex. The H-bonds are depicted as grey lines. Only polar hydrogens are shown [49]. (For interpretation of the references to colour in this figure legend, the reader is referred to the web version of this article.)

their direct and selective interaction with the Syt1-C2B domain, thus unravelling a possible mechanism of action. This interaction was rationalized through molecular dynamics simulations, indicating that the binding site for these peptides partially overlaps to the first hot-spot identified in the SNARE-Syt-1 complex, involving $N$ - and $C$-terminal SNAP25 interface. A similar network of polar and hydrophobic interactions was found. This interacting model explains the $\mathrm{K}_{\mathrm{D}}$ values and the selectivity towards Syt7 protein. Interestingly, the palmitoylated 2,5-cyclic peptide 12 displays in vivo analgesic activity in a model of thermal hyperalgesia provoked by Freund's adjuvant (CFA). To the best of our knowledge, this is the first experimental evidence of analgesic peptides acting by direct interaction with the Syt1 protein. The results from this work represent a significant advancement in the understanding of the mechanism of action of DD04107 (1) and congener exocytotic peptides. Taken together, these results indicate that Syt1 could be considered a new target toward improved peptide/peptidomimetic analgesic agents.

\section{Experimental procedures}

\subsection{Synthetic procedures}

General: All reagents were of commercial quality. Amino acid derivatives: Fmoc-Ala-OH, Fmoc-Arg(Pbf)-OH, Fmoc-Gln(Trt)-OH, FmocMet-OH, Fmoc-Glu(tBu)-OH, Fmoc-Glu(OAll)-OH, Fmoc-Lys(Alloc)$\mathrm{OH}$ (IRIS BIOTECH and BACHEM). Other reagents used $\mathrm{Ac}_{2} \mathrm{O}, \mathrm{EDT}, \mathrm{TFA}$, $\mathrm{Pd}\left(\mathrm{PPh}_{3}\right)_{4}$ and $\mathrm{PhSiH}_{3}$, TIS (ALDRICH), PyAOP, HOAt, HCTU, DIEA, Pd $\left(\mathrm{PPh}_{3}\right)_{4}$ and $\mathrm{PhSiH}_{3}$ (FLUKA) and Rink Amide MBHA resin (100-200 mesh, $0.34 \mathrm{mmol} / \mathrm{g}$ ) from NOVABIOCHEM.

Resins were swollen in DCM/DMF $(3 \times 0.5 \mathrm{~min})$.

\subsubsection{General coupling procedure}

Rink Amide MBHA (100 mg, $0.034 \mathrm{mmol}$ ) previously swollen, was treated with $20 \%$ piperidine in DMF $(1 \times 5 \mathrm{~min})$ and $(1 \times 20 \mathrm{~min})$ and washed with DMF/DCM/DMF $(5 \times 0.5 \mathrm{~min})$. Then a solution of the corresponding C-terminal amino acid $(0.068 \mathrm{mmol})$ in anhydrous DMF (1 mL), O-(1H-6-Chlorobenzotriazole-1-yl)-1,1,3,3-tetramethyluronium hexafluorophosphate (HCTU, $28 \mathrm{mg}, 0.068 \mathrm{mmol})$ and DIEA $(12 \mu \mathrm{L}$, $0.068 \mathrm{mmol}$ ) were added. The coupling was allowed to proceed at $\mathrm{rt}$ for $1 \mathrm{~h}$. Each coupling was checked by the Kaiser test and repeated if 
necessary. After the coupling is finished, the resin was drained and washed with DMF/DCM ( $5 \mathrm{x} 0.5 \mathrm{~min}$ ). Manual synthesis was performed repeating the cycle described above for each amino acid until the sequence is completed.

\subsubsection{General acetylation procedure}

The Fmoc-resin-bound peptide, previously swollen, was treated with $20 \%$ piperidine in DMF $(1 \times 5 \mathrm{~min})$ and $(1 \times 20 \mathrm{~min})$ and washed with DMF/DCM/DMF $(5 \times 0.5 \mathrm{~min})$. Then, a solution of $\mathrm{Ac}_{2} \mathrm{O}(20 \mathrm{eq})$, diisopropylethylamine (DIEA, $20 \mathrm{eq})$ in DMF (1 mL) was added and reacted at $\mathrm{rt}$ for $1 \mathrm{~h}$.

\subsubsection{General palmitoylation procedure}

The Fmoc-resin-bound peptide, previously swollen, was treated with $20 \%$ piperidine in DMF $(1 \times 5 \mathrm{~min})$ and $(1 \times 20 \mathrm{~min})$ and washed with $\mathrm{DMF} / \mathrm{DCM} / \mathrm{DMF}(5 \times 0.5 \mathrm{~min})$. Then, it was treated with palmitic acid ( 2 equiv), HCTU ( 2 equiv), DIEA ( 2 equiv) in anhydrous DMF ( $1 \mathrm{~mL}$ ) for $1 \mathrm{~h}$.

4.1.4. General procedure for removing of Alloc and OAll protecting groups

The resin bound derivative, previously swollen, was purged with $\mathrm{Ar}$ and treated with a solution of $\mathrm{Pd}\left(\mathrm{PPh}_{3}\right)_{4}(10 \mathrm{mg}, 0.008 \mathrm{mmol})$ and $\mathrm{PhSiH}_{3}(0.1 \mathrm{~mL}, 0.82 \mathrm{mmol})$ in DCM $(2 \mathrm{~mL})$. The reaction mixture was stirred for $45 \mathrm{~min}$. This procedure was repeated once more. The resin was washed with DCM/DMF/Et ${ }_{2} \mathrm{NCS}_{2} \mathrm{Na}(0.02 \mathrm{M}) / \mathrm{DMF} / \mathrm{DCM}(4 \times 0.5$ $\min )$.

\subsubsection{Cyclization reaction}

After removing of OAll and Alloc protecting groups, the resin-bound peptide (100 mg, $0.034 \mathrm{mmol})$, previously swollen, was treated with a solution of PyAOP (177 mg, $0.34 \mathrm{mmol}$ ), HOAt ( $46 \mathrm{mg}, 0.34 \mathrm{mmol}$ ), DIEA ( $0.12 \mathrm{~mL}, 0.68 \mathrm{mmol})$ in anhydrous DMF $(2 \mathrm{~mL})$. The reaction was allowed to proceed at room temperature or under microwave irradiation $\left(120^{\circ} \mathrm{C}\right)$ for $1 \mathrm{~h}$, until ninhydrine test was negative. The resin was washed and drained with DMF/DCM/DMF/DCM $(4 \times 0.5 \mathrm{~min})$.

\subsubsection{General cleavage procedure}

The resin bound peptide was treated with $1 \mathrm{~mL}$ of TFA/ethanedithiol (EDT) $/ \mathrm{H}_{2} \mathrm{O} / \mathrm{TIS}$ (94:2.5:2.5:1) for $3 \mathrm{~h}$ at room temperature. The resin was filtered off and crude products were precipitated with cold $\mathrm{Et}_{2} \mathrm{O}$. The resulting solid was centrifuged and washed twice with ether, and then lyophilized.

Peptides were isolated in high purity (95-99\%) after reverse phase MPLC using SNAP $12 \mathrm{~g}$ KP-C18-HS cartridges in an ISOLERA ONE (BIOTAGE). Acetyl linear peptides (2-8) and cyclo peptides (9-11) were purified with a gradient of $\mathrm{CH}_{3} \mathrm{CN}: \mathrm{H}_{2} \mathrm{O}(0.05 \%$ TFA) from $0: 100$ to 100:0 and palmitoyl peptide (1) with an initial gradient $2-5 \%$ of $\mathrm{CH}_{3} \mathrm{CN}$, with a flux of $12 \mathrm{~mL} / \mathrm{min}$ and visualization at $200-214 \mathrm{~nm}$. The purity of all peptides was analyzed using an analytical HPLC Agilent, with a column ACE 5 C18-300 (4,6 $\mathrm{mm} \times 150 \mathrm{~mm}, 300 \mathrm{~A})$ at $1 \mathrm{~mL} / \mathrm{min}$, with a gradient of $\mathrm{CH}_{3} \mathrm{CN}$ [solvent $\mathrm{A}$ ]: $\mathrm{H}_{2} \mathrm{O}(0.005 \%$ TFA) [solvent $\mathrm{B}$ ] of $2-30 \%$ of $\mathrm{A}$ in $15 \mathrm{~min}$ for acetylated derivatives and $20-95 \%$ in $15 \mathrm{~min}$ for palmytoylated analogues.

The purity of all peptides and their characterization was performed by HPLC-MS (Waters) coupled to a single quadrupole ESI-MS (Micromass ZQ 2000) at $1 \mathrm{~mL} / \mathrm{min}$ with a SUNFIRE ${ }^{\mathrm{TM}}$ column C18 (3.5 $\mu, 4.6$ $\times 50 \mathrm{~mm})$, gradient of $\mathrm{CH}_{3} \mathrm{CN}\left(0.005 \% \mathrm{HCO}_{2} \mathrm{H}\right)$ [solvent $\left.\mathrm{A}\right]: \mathrm{H}_{2} \mathrm{O}$ $\left(0.005 \% \mathrm{HCO}_{2} \mathrm{H}\right)$ [solvent $\mathrm{B}$ ] as mobile phase in $15 \mathrm{~min}$. Acetyl peptides and cyclo peptides were studied with a gradient from 2 to 10 and the palmitoyl analogue with a gradient from 2 to 95 of solvent A. HRMS (EI + ) was carried out in an Agilent 6520 Accurate-Mass Q-TOF LC/MS equipment.

\subsubsection{Characterization of compounds 1-8}

Peptides 1-8 were obtained following the general coupling and acetylation procedure. After cleavage, they were purified by reverse phase MPLC as described above in the general methods.

Pal-EEMQRR-NH $\mathrm{N}_{2}$ (1): Yield: 31\%. Purity: 99\%. HPLC-MS: $t_{R}=$ 10.74 min. EM-MS: Calculated 1085.64; Experimental, 1086.06 $[\mathrm{M}+\mathrm{H}]^{+}, \quad 543.42 \quad[\mathrm{M}+2 \mathrm{H} / 2]^{2+}$. Exact Mass calculated for $\mathrm{C}_{48} \mathrm{H}_{88} \mathrm{~N}_{14} \mathrm{O}_{12} \mathrm{~S}: 1084,64269$, found: 1084.64308 .

Ac-EEMQRR-NH $\mathrm{N}_{2}$ (2): Yield: 53\%. Purity: 99\%. HPLC: $\mathrm{t}_{\mathrm{R}}=9.53$ min. EM-MS: Calculated, 889.00; Experimental, $889.7[\mathrm{M}+\mathrm{H}]^{+}, 445.21$ $[\mathrm{M}+2 \mathrm{H} / 2]^{2+}$. Exact Mass calculated for $\mathrm{C}_{34} \mathrm{H}_{60} \mathrm{~N}_{14} \mathrm{O}_{12} \mathrm{~S}: 888.42358$, found: 888.42402.

Ac-EEMQRA-NH $\mathrm{N}_{2}$ (3): Yield: 85\%. Purity: 97\%. HPLC: $\mathrm{t}_{\mathrm{R}}=11.28$ min. EM-MS: Calculated, 803.89, Experimental, 805.6 $[\mathrm{M}+\mathrm{H}]^{+}, 402.83$ $[\mathrm{M}+2 \mathrm{H} / 2]^{2+}$. Exact Mass calculated for $\mathrm{C}_{31} \mathrm{H}_{53} \mathrm{~N}_{11} \mathrm{O}_{12} \mathrm{~S}$ : 803.35959, found: 803.36107 .

Ac-EEMQAR-NH $\mathrm{N}_{2}$ (4): Yield: 59\%. Purity: 95.5\%. HPLC: $\mathrm{t}_{\mathrm{R}}=10.23$ min. EM-MS: Calculated, 803.89, Experimental, $804.60[\mathrm{M}+\mathrm{H}]^{+}$. Exact Mass calculated for $\mathrm{C}_{31} \mathrm{H}_{53} \mathrm{~N}_{11} \mathrm{O}_{12} \mathrm{~S}$ : 803.35959, found: 803.36187.

Ac-EEMARR-NH $\mathrm{N}_{2}$ (5): Yield: 69\%. Purity: 97\%. HPLC: $\mathrm{t}_{\mathrm{R}}=11.48$ min. EM-MS: Calculated, 831.95, Experimental, $832.58[\mathrm{M}+\mathrm{H}]^{+}$, $416.81[\mathrm{M}+2 \mathrm{H} / 2]^{2+}$. Exact Mass calculated for $\mathrm{C}_{32} \mathrm{H}_{57} \mathrm{~N}_{13} \mathrm{O}_{12} \mathrm{~S}$ : 831.40212, found: 831.39974.

Ac-EEAQRR-NH $\mathrm{N}_{2}$ (6): Yield: 53\%. Purity: 97\%. HPLC: tR $=3.81$ min. EM-MS: Calculated, 828.89, Experimental, $829.51[\mathrm{M}+\mathrm{H}]^{+}$, 415.27 $[\mathrm{M}+2 \mathrm{H} / 2]^{2+}$. Exact Mass calculated for $\mathrm{C}_{32} \mathrm{H}_{56} \mathrm{~N}_{13} \mathrm{O}_{14}$ : 828.42021, found: 828.42147.

Ac-EAMQRR- $\mathrm{NH}_{2}$ (7): Yield: $82 \%$. Purity: 97\%. HPLC: $t_{R}=7.92$ min. EM-MS: Calculated, 830.96, Experimental, $831.67[\mathrm{M}+\mathrm{H}]^{+}$, $416.32[\mathrm{M}+2 \mathrm{H} / 2]^{2+}$. Exact Mass calculated for $\mathrm{C}_{32} \mathrm{H}_{58} \mathrm{~N}_{14} \mathrm{O}_{10} \mathrm{~S}$ : 830.41810, found: 830.41933.

Ac-AEMQRR-NH $\mathrm{N}_{2}$ (8): Yield: $60 \%$. Purity: 97\%. HPLC: $\mathrm{t}_{\mathrm{R}}=8.82$ min. EM-MS: Calculated, 830.96, Experimental, $831.67[\mathrm{M}+\mathrm{H}]^{+}$, $416.32[\mathrm{M}+2 \mathrm{H} / 2]^{2+}$. Exact Mass calculated for $\mathrm{C}_{32} \mathrm{H}_{58} \mathrm{~N}_{14} \mathrm{O}_{10} \mathrm{~S}$ : 830.41810, found: 830.41370 .

\subsubsection{Characterization of compounds $\mathbf{9 - 1 2}$}

After elongation of the peptides and acetylation following general procedure, the Alloc and OAll groups were removed from the resinbounded derivatives. Then, lactamization reaction was allowed to proceed at room temperature overnight or $\mathrm{MW}\left(120^{\circ} \mathrm{C}\right)$ for $1 \mathrm{~h}$. After cleavage, the cyclo peptides were purified by reverse phase MPLC, as described above in the general methods.

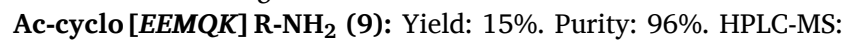
$\mathrm{t}_{\mathrm{R}}=7.69$ min. EM-MS: Calculated, 842.97, Experimental, 844.00 $[\mathrm{M}+\mathrm{H}]^{+}, \quad 422.00 \quad[\mathrm{M}+2 \mathrm{H} / 2]^{2+}$. Exact Mass calculated for $\mathrm{C}_{34} \mathrm{H}_{58} \mathrm{~N}_{12} \mathrm{O}_{11} \mathrm{~S}: 842.40687$, found: 842.40680.

Ac-E-cyclo [EMQK] R-NH $\mathrm{NH}_{2}$ (10): Yield: 25\%. Purity: 97\%. HPLCMS: $t_{R}=5.83$ min. EM-MS: Calculated, 842.97, Experimental, 843.64 $[\mathrm{M}+\mathrm{H}]^{+}, \quad 422.38[\mathrm{M}+2 \mathrm{H} / 2]^{2+}$. Exact Mass calculated for $\mathrm{C}_{34} \mathrm{H}_{58} \mathrm{~N}_{12} \mathrm{O}_{11} \mathrm{~S}:$ 842.40687, found: 842.40366.

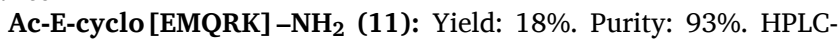
MS: $t_{R}=6.39$ min. EM-MS: Calculated, 842.97, Experimental, 844.00 $[\mathrm{M}+\mathrm{H}]^{+}, \quad 422.00 \quad[\mathrm{M}+2 \mathrm{H} / 2]^{2+}$. Exact Mass calculated for $\mathrm{C}_{34} \mathrm{H}_{58} \mathrm{~N}_{12} \mathrm{O}_{11} \mathrm{~S}: 842.40687$, found: 842.40372.

Pal-E-cyclo [EMQK] R-NH $\mathrm{NH}_{2}$ (12): Yield: 7\%. Purity: 96\%. HPLC-MS: $\mathrm{t}_{\mathrm{R}}=11.45$ min. EM-MS: Calculated, 1039.35, Experimental, 1040.1 $[\mathrm{M}+\mathrm{H}]^{+}, \quad 520.6[\mathrm{M}+2 \mathrm{H} / 2]^{2+}$. Exact Mass calculated for $\mathrm{C}_{48} \mathrm{H}_{86} \mathrm{~N}_{12} \mathrm{O}_{11} \mathrm{~S}: 1038.6259$, found: 1038.6292 .

\subsection{Circular dicroism}

CD spectra were recorded on a Jasco J-810 instrument equipped with a Peltier temperature control unit using a quartz glass cell of $0.1 \mathrm{~cm}$ path length. Ellipticity was measured between 250 and $190 \mathrm{~nm}$ for samples at peptide concentrations of $50 \mu \mathrm{M}$ in both $\mathrm{H}_{2} \mathrm{O}$ and in $30 \%$ TFE- $\mathrm{H}_{2} \mathrm{O}$ solutions at $5{ }^{\circ} \mathrm{C}$. Four repeats scans at a scan rate of $50 \mathrm{~nm} \cdot \mathrm{min}^{-1}, 2 \mathrm{~s}$ response time and $1 \mathrm{~nm}$ band width, were averaged for each sample and for the baseline of the corresponding peptide-free sample. Once the 
baseline is corrected, $\mathrm{CD}$ data were converted into mean residue ellip-

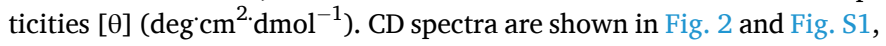
SM.

\subsection{NMR structural study}

NMR samples were prepared by solving the amount of lyophilized peptide required to get an approximately $1 \mathrm{mM}$ concentration in either $\mathrm{H}_{2} \mathrm{O} / \mathrm{D}_{2} \mathrm{O}\left(9: 1 \mathrm{v} / \mathrm{v}\right.$ ) or in $30 \%$ vol. 2,2,2-trifluoroethanol (TFE) in $\mathrm{H}_{2} \mathrm{O}$ at $\mathrm{pH}$ 5.5. Sample $\mathrm{pH}$ was measured with a glass microelectrode, not corrected for isotope effects and adjusted, if necessary, by adding minimal amounts of NaOD or DCl. Sodium 2,2-dimethyl-2-silapentane-5-sulfonate (DSS) was added as an internal reference.

NMR spectra were recorded on a Bruker AV-600 spectrometer operating at a $600.13 \mathrm{MHz}$ proton frequency and equipped with a cryoprobe. Probe temperature was calibrated using a methanol sample. $1 \mathrm{D}{ }^{1} \mathrm{H}$ spectra were recorded using $32 \mathrm{~K}$ data points, which were zerofilled to $64 \mathrm{~K}$ prior to Fourier transformations. 2D spectra, i.e., phasesensitive correlated spectroscopy (COSY), total correlated spectroscopy (TOCSY), nuclear Overhauser enhancement spectroscopy (NOESY), rotating frame nuclear Overhauser spectroscopy (ROESY) and ${ }^{1} \mathrm{H}_{-}{ }^{13} \mathrm{C}$ heteronuclear single quantum coherence spectra (HSQC) at natural ${ }^{13} \mathrm{C}$ abundance, were acquired by standard pulse sequences using the time-proportional phased increment mode. Presaturation was used to suppress the water signal. Mixing times were $60 \mathrm{~ms}$ for TOCSY, 150 or $200 \mathrm{~ms}$ for NOESY, and $200 \mathrm{~ms}$ for ROESY. Spectra were processed using the TOPSPIN program [50]. 2D data matrices, which were acquired with $2048 \times 512$ points in $t_{2}$ and $t_{1}$, respectively, were multiplied by a square-sine bell window function (a sine-bell in COSY spectra) with the shift optimized for every spectrum and zero-filled to 2 $\times 1 \mathrm{~K}$ complex matrices prior to Fourier transformation. Baseline was corrected in both dimensions. The ${ }^{13} \mathrm{C} \delta$-values were indirectly referenced using the IUPAC-recommended ${ }^{13} \mathrm{C} /{ }^{1} \mathrm{H}$ ratio 0.25144953 [51].

${ }^{1} \mathrm{H}$ and ${ }^{13} \mathrm{C}$ chemical shifts were assigned in aqueous solution and in $30 \%$ TFE (v/v) at 5 and $25^{\circ} \mathrm{C}$ (see Tables S1-S8, SM) by joint analysis of 2D COSY, TOCSY, NOESY and ROESY spectra following the standard sequential strategy [52], which were examined in combination with 2D ${ }^{1} \mathrm{H}_{-}{ }^{13} \mathrm{C}$ HSQC spectra using the program Sparky (SPARKY).

The $\Delta \delta / \Delta \mathrm{T}$ values for the amide $\mathrm{H}_{\mathrm{N}}$ protons were obtained from the chemical shifts measured at 5 and $25{ }^{\circ} \mathrm{C}$ (Tables S1-S8).

Quantification of helix populations was done from the $\Delta \delta_{\mathrm{H} \alpha}$ and $\Delta \delta_{\mathrm{C} \alpha}$ values averaged for the helical residues (all residues were considered in peptides 2, 9-11), as previously described [53,54]. $\Delta \delta_{\mathrm{H} \alpha}$ and $\Delta \delta_{\mathrm{C} \alpha}$ values are defined as follows: $\Delta \delta_{\mathrm{H} \alpha}=\delta_{\mathrm{H} \alpha}{ }^{\text {observed }}-\delta_{\mathrm{H} \alpha}$ random coil, $\mathrm{ppm}$, and $\Delta \delta_{\mathrm{C} \alpha}=\delta_{\mathrm{C} \alpha}^{\text {observed }}-\delta_{\mathrm{C} \alpha}^{\text {random coil }}$, ppm; being $\delta_{\mathrm{H} \alpha}^{\text {random coil and }}$ $\delta_{\mathrm{C} \alpha}{ }^{\text {random coil }}$ taken from reference 22 . The reference values for $100 \%$ helix were $-0.39 \mathrm{ppm}$ [27] and $+3.09 \mathrm{ppm}$ [55] for $\Delta \delta_{\mathrm{H \alpha}}$ and $\Delta \delta_{\mathrm{C} \alpha}$, respectively.

Structures for peptides 2, 9 and $\mathbf{1 1}$ were calculated using the CYANA program [56,57], and on the basis of: i) distance constraints derived from the experimentally observed NOE/ROE, and ii) $\phi, \psi$ dihedral angle restraints obtained from the ${ }^{1} \mathrm{H}_{\alpha},{ }^{13} \mathrm{C}_{\alpha}$ and ${ }^{13} \mathrm{C}_{\beta}$ chemical shifts using the TALOS-N server [58]. To get the distance restraints, NOESY and ROESY peak volumes were obtained by the automatic integration function of Sparky [59]. The structures of peptides 9 and 11, which exhibit a large helix population in aqueous solution (about 70\%; Table S10, SM), were calculated by applying the automatic protocol implemented in CYANA [56]. The protocol consists of seven iterative cycles of automatic NOE assignment and structure calculation, followed by a final step of standard structure calculation. Each cycle starts from 100 randomized conformers, and for each peptide the final structure is composed of the 20 lowest target function conformers resulting at the final step. This automatic protocol was not applied to peptide 2 because of its low helix population even in $30 \%$ TFE ( $28 \%$; Table S10, SM). In these cases, nonhelical conformers affect the intensity of intra-residue and most sequential NOEs. Therefore, as done in other cases of low-populated structures [52], calculation was done using only the distance restraints derived from the non-sequential and the helix-characteristic NH-NH sequential NOEs, plus the $\phi, \psi$ dihedral angle restraints, and following a standard CYANA annealing structure calculation. Structures were visualized and analyzed using the MOLMOL program [60].

\subsection{Expression and purification of Syt1 $C 2 B$ and Syt7 $C 2 B$}

Expression vectors to obtain rat synaptotagmin 1 and synaptotagmin 7 C2B domains (residues 271-421 and 260-403 respectively) as GST fusion proteins were kindly provided by Dr. J. Rizo. The previously described expression and purification steps were followed [61,62]. Briefly, BL21(DE3) E. coli strain was transformed and cells containing the vectors were grown at $37{ }^{\circ} \mathrm{C}$ in $\mathrm{LB}$ medium. Once the cells reached the exponential growth step, the protein expression was induced adding Isopropyl $\beta$ - D - 1-thiogalactopyranoside (IPTG) $0.4 \mathrm{mM}$. After $4 \mathrm{~h}$ cells were lysated by sonication and the lysate was incubated at $4{ }^{\circ} \mathrm{C}$ with glutathione-agarose beads. After several wash steps thrombin was added to the beads and the eluted mobile phase containing the cleavaged protein was collected and polished by cation exchange chromatography.

\subsection{CGRP release assay}

Exocytotic CGRP release was determined as described [16]. Neonatal dorsal rootganglia from Wistar rats (3-5 days-old) were isolated and located into a Petri dish containing DMEM-glutamax with $1 \% \mathrm{P} / \mathrm{S}(5000$ $\mathrm{U} / \mathrm{mL})$. After removing roots, ganglia were digested with $0.25 \%(\mathrm{w} / \mathrm{v})$ collagenase (type IA) in DMEM-glutamax with $1 \% \mathrm{P} / \mathrm{S}$ for $1 \mathrm{~h}\left(37^{\circ} \mathrm{C}, 5 \%\right.$ $\mathrm{CO}_{2}$, ThermoScientific incubator). After digestion, DRGs were mechanically dissociated using a glass Pasteur pipette. Single cell suspension was passed through a $100 \mu \mathrm{m}$ cell strainer, and washed with DMEM Glutamax plus $10 \% \mathrm{FBS}$ and $1 \% \mathrm{P} / \mathrm{S}$. After centrifugation at 300xg for 5 min, cells were resuspended in DMEM glutamax, $10 \% \mathrm{FBS}$ and $1 \% \mathrm{P} / \mathrm{S}$, supplemented with $50 \mathrm{ng} / \mathrm{mL} 2.5 \mathrm{~s}$ NGF and $1.25 \mu \mathrm{g} / \mathrm{mL}$ cytosine arabinoside. Cells seeded in 96-well plate previously coated with poly-Llysine $(8.33 \mu \mathrm{g} / \mathrm{ml})$ and laminin $(5 \mu \mathrm{g} / \mathrm{ml})$ at 50.000 cells/well in 200 $\mu \mathrm{L}$. After $48 \mathrm{~h}$ seeding $\left(37{ }^{\circ} \mathrm{C}, 5 \% \mathrm{CO}_{2}\right)$, medium was replaced by external solution in mM: $140 \mathrm{NaCl}, 4 \mathrm{KCl}, 2 \mathrm{MgCl}_{2}, 2 \mathrm{CaCl}_{2}, 10$ Hepes, 5 Glucose, 20 D-Mannitol, $\mathrm{pH}$ 7.4. After medium removal, cells were incubated for $1 \mathrm{~h}\left(37^{\circ} \mathrm{C}, 5 \% \mathrm{CO}_{2}\right)$ with peptides at $100 \mu \mathrm{M}$, dissolved in $37{ }^{\circ} \mathrm{C}$ extracellular fresh solution. Then, cells were carefully washed with extracellular solution and incubated with $100 \mu \mathrm{L}$ of $1 \mu \mathrm{M}$ capsaicin in external solution for $10 \mathrm{~min}\left(37{ }^{\circ} \mathrm{C}, 5 \% \mathrm{CO}_{2}\right)$. CGRP content was determined in supernatants using the commercially available CGRP EIA (Spi-Bio Inc). Animal procedures approved by the University Miguel Hernández de Elche Institutional Animal and Ethical Committee in accordance with the guidelines of the Economic European Community. Each peptide was tested in parallel in 3 independent primary cultures of nociceptors. The number of neonatal Wistar rats used per primary nociceptor culture was 3 (total number 9 animals).

\subsection{Isothermal titration calorimetry (ITC)}

Interaction of Syt1 C2B and Syt7 C2B with the peptides was analyzed with an Auto-iTC200 isothermal titration calorimeter (MicroCal, Malvern-Panalytical) at a constant temperature of $25^{\circ} \mathrm{C}$. Protein solution was used at a final concentration of $40 \mu \mathrm{M}$ in buffer $5 \mathrm{mM}$ MES pH 6.1, $20 \mathrm{mM} \mathrm{NaCl}, 2 \mathrm{mM} \mathrm{CaCl}_{2}$. Peptide solutions at $400 \mu \mathrm{M}$ in the same buffer were injected following programmed sequences of $2 \mu \mathrm{L}$ injections $(0.5 \mu \mathrm{L} / \mathrm{s}$ injection rate) with a spacing of $150 \mathrm{~s}$ and a stirring speed of 750. Two independent calorimetric titrations $(n=2)$ were performed for each interaction, in order to assess reproducibility, as well as to estimate average values for the dissociation constants and their errors. The dissociation constants were obtained through nonlinear least squares regression analysis of the experimental data to a model considering a single ligand binding site each peptide in Syt1. Appropriate controls 
were performed: 1) calcium-EDTA titrations to test the calorimeter; and 2) peptide dilution into buffer in order to evaluate the heat effect associated with that process.

\subsection{Thermal hyperalgesia in vivo assay}

\subsubsection{Animals}

Swiss male mice (28-32 g) from the Animalario of the Universidad de Oviedo (Reg. 33,044 13A) exposed to a light-dark cycle of $12 \mathrm{~h}$ and with free access to water and food were used. Experiments were approved by the Comité Ético de Experimentación Animal of the Universidad de Oviedo (Spain) and carried out in accordance with the EU Directive 2010/63/EU for the Protection of Laboratory Animals. Mice were employed only once.

\subsubsection{Drugs}

For intraplantar (i.pl.) injection animals were carefully immobilized in a small plastic tube leaving the hindpaw exposed for the injection. Inflammation was induced by i.pl. administration into the right hind paw of $25 \mu \mathrm{L}$ of complete Freund's adjuvant (CFA, Sigma). Control mice received an i.pl. injection of the same volume of saline. Nociceptive responses were tested $24 \mathrm{~h}$ after CFA injection. Peptide 12 stock was dissolved in DMSO (Sigma) and diluted in saline for injections.

\subsubsection{Unilateral hot plate}

As previously described $[17,63]$, mice were gently restrained and the plantar side of the tested paw placed on a hot plate (IITC Life Science) set at $48.6^{\circ} \mathrm{C}$. Measurements of withdrawal latencies from the heated surface of each hind paw were made separately at 2-min intervals, and the mean of two measures was considered. A cut-off of $30 \mathrm{~s}$ was established.

\subsubsection{Statistics}

GraphPad Prism (Graph- Pad Software Inc., San Diego, CA) software were used for all statistical analyses. Two-way ANOVA with Bonferroni post hoc test. $* P<0.05 ; * * * * P<0.0001$.

\subsection{Molecular docking studies}

Ligands and proteins were prepared using LigPrep [39] and Protein Preparation Wizard applications [40,41], respectively, in the Schrödinger Suite release 2017-3 (LigPrep, Schrödinger, LCC, New York, NY, 2017). The 3D structure of Syt1 was got from the Syt1-SNARE complex (pdb code 5KJ7) [45].

The docking site was defined as a cubic box, the inner box of $10 \AA$ centered on residues E295, K297, N336, Y338 and W404 of Syt1. For these studies we applied the Induced Fit Docking protocol ${ }^{33-35}$ within the Schrödinger suite of programs that allow certain flexibility of the protein. Initially, this protocol docked the ligand into the fixed protein using Glide, and to reduce steric clashes the van der Waals radii (rdW) of both protein and ligands are scaled to 0.5 . Next, to optimize the sidechains of the residues within $5 \AA$ of the ligand poses, Prime was used. Finally, the ligands were redocked using Glide into the new receptor conformations generated using the default rdW radii. The poses are ranked using IFD score. The selection was based on the best ranked conformation of each ligand and visual inspection.

The best poses were selected for simulated annealing molecular dynamics studies, to allow for flexibility of the whole complexes. In these studies, we used the Amber 16 and the FF12B force field $[47,48]$. The complexes were solvated in a octahedral box using TIP3P water molecules extended $10 \AA$ away from any protein atom. The system was neutralized by $\mathrm{Cl}^{-}$counter ion and periodic boundary conditions were used. The structures were minimized by steepest descent for 5000 steps, then switches to conjugate gradient for another 5000 steps. Subsequently, the system was heated gradually from $0 \mathrm{~K}$ to at $300 \mathrm{~K}$ over 100 ps, using positional restrains, starting with a restraint weight of $5.0 \mathrm{Kcal}$ $\mathrm{mol}^{-1} \mathrm{~A}^{-2}$ and an integration time step of $1.0 \mathrm{fs}$. In the first $25 \mathrm{ps}$, the water and counter-ions were equilibrated, while the solutes were restrained, then, progressively weaker restraints were applied till all were removed in the last $100 \mathrm{ps}$ under the NPT ensemble. The temperature was maintained at $300 \mathrm{~K}$ using Langevin dynamics. Once the system was equilibrated, $60 \mathrm{~ns}$ of production simulation was running, with an integration time step of $2.0 \mathrm{fs}$ and hydrogen bonds constrained using the SHAKE algorithm. The particle Mesh Ewald method was used for the calculation of electrostatic interactions. The analysis of the molecular dynamics studies led to the identification of the complex depicted in this paper.

For visualization and making figures the PyMOL Molecular Graphic System v1.8 [49] was used.

\section{Declaration of Competing Interest}

The authors declare that they have no known competing financial interests or personal relationships that could have appeared to influence the work reported in this paper.

\section{Acknowledgements}

This work was supported by the Spanish Ministerio de Economía y Competitividad (MINECO-FEDER), RTI2018-097189-C2 and CTQ201784371-P), and the Spanish National Research Council (CSIC, 201880E109, 201980E030). The NMR experiments were performed in the "Manuel Rico" NMR laboratory, LMR, CSIC, a node of the Spanish Large-Scale National Facility ICTS R-LRB. We thank Prof. Josep Rizo and R. Voleti (Dept. Biophysics, Biochemistry and Pharmacology, UT Southwestern Medical Center, Dallas, USA) for providing the clones required for expressing Syt1 and Syt7 proteins. SG-R and AB belong to the Instituto de Investigación Sanitaria del Principado de Asturias (ISPA).

\section{Appendix A. Supplementary data}

Supplementary data to this article can be found online at https://doi. org/10.1016/j.bioorg.2021.105231.

\section{References}

[1] S.N. Raja, D.B. Carr, M. Cohen, N.B. Finnerup, N.B. Finnerup, H. Flor, S. Gibson, F. J. Keefe, J.S. Mogil, M. Ringkamp, K.A. Sluka, X.-J. Song, B. Stevens, M.D. Sullivan, P.R. Tutelman, T. Ushida, K. Vader, The revised International Association for the Study of Pain definition of pain: concepts, challenges, and compromises, Pain (2020).

[2] D. Borsook, A.M. Youssef, D. Borsook, D. Borsook, D. Borsook, L. Simons, I. Elman, C. Eccleston, C. Eccleston, When pain gets stuck: the evolution of pain chronification and treatment resistance, Pain. 159 (2018) 2421-2436.

[3] C. Allerton, ed., Pain therapeutics : current and future treatment paradigms, RSC Publishing, 2014.

[4] M.J. Perez de Vega, A. Ferrer-Montiel, R. Gonzalez-Muniz, Recent progress in nonopioid analgesic peptides, Arch. Biochem. Biophys. 660 (2018) 36-52, https://doi. org/10.1016/j.abb.2018.10.011.

[5] S. Iyengar, M.H. Ossipov, K.W. Johnson, The role of calcitonin gene-related peptide in peripheral and central pain mechanisms including migraine, Pain. 158 (2017) 543-559, https://doi.org/10.1097/j.pain.0000000000000831.

[6] I. Devesa, C. Ferrándiz-Huertas, S. Mathivanan, C. Wolf, R. Luján, J.-P. Changeux, A. Ferrer-Montiel, $\alpha$ CGRP is essential for algesic exocytotic mobilization of TRPV1 channels in peptidergic nociceptors, Proc. Natl. Acad. Sci. U. S. A. 111 (2014) 18345-18350, https://doi.org/10.1073/pnas.1420252111.

[7] P.R. Holland, P.J. Goadsby, Targeted CGRP Small Molecule Antagonists for Acute Migraine Therapy, Neurotherapeutics. 15 (2018) 304-312, https://doi.org/ 10.1007/s13311-018-0617-4.

[8] Z. Lacković, B. Filipović, I. Matak, Z. Helyes, Activity of botulinum toxin type A in cranial dura: implications for treatment of migraine and other headaches, Br. J. Pharmacol. 173 (2016) 279-291, https://doi.org/10.1111/bph.13366.

[9] V. Drinovac Vlah, B. Filipović, L. Bach-Rojecky, Z. Lacković, Role of central versus peripheral opioid system in antinociceptive and anti-inflammatory effect of botulinum toxin type A in trigeminal region, Eur. J. Pain. 22 (2018) 583-591, https://doi.org/10.1002/ejp.1146.

[10] S. Luvisetto, F. Pavone, P. Gazerani, C. Cianchetti, Botulinum Toxin Type a as a Therapeutic Agent against Headache and Related Disorders, Toxins (Basel). 7 (2015) 3818-3844. 
[11] B. Chiu, S.-D. Chung, H.-C. Tai, S.-D. Chung, L.A. Birder, L.A. Birder, Botulinum Toxin A for Bladder Pain Syndrome/Interstitial Cystitis, Toxins (Basel). 8 (2016) 201.

[12] E. Rojewska, A. Piotrowska, K. Popiolek-Barczyk, J. Mika, Botulinum Toxin Type A-A Modulator of Spinal Neuron-Glia Interactions under Neuropathic Pain Conditions, Toxins (Basel). 10 (2018) 145.

[13] T.N. Joshi, S. Joshi, Adverse effects of Botulinum neurotoxin A in spasticity management, Int. J. Nutr. Pharmacol. Neurol. Dis. 1 (2011) 126-133, https://doi. org $/ 10.4103 / 2231-0738.84202$.

[14] P. Baskaran, T.E. Lehmann, E. Topchiy, N. Thirunavukkarasu, S. Cai, B.R. Singh, S. Deshpande, B. Thyagarajan, Effects of enzymatically inactive recombinant botulinum neurotoxin type $A$ at the mouse neuromuscular junctions, Toxicon. 72 (2013) 71-80, https://doi.org/10.1016/j.toxicon.2013.06.014.

[15] C. Blanes-Mira, J.M. Merino, E. Valera, G. Fernandez-Ballester, L.M. Gutierrez, S. Viniegra, E. Perez-Paya, A. Ferrer-Montiel, Small peptides patterned after the Nterminus domain of SNAP25 inhibit SNARE complex assembly and regulated exocytosis, J. Neurochem. 88 (2004) 124-135, https://doi.org/10.1046/j.1471 4159.2003.02133.x.

[16] M. Camprubi-Robles, R. Planells-Cases, A. Ferrer-Montiel, Differential contribution of SNARE-dependent exocytosis to inflammatory potentiation of TRPV1 in nociceptors, FASEB J. 23 (2009) 3722-3733, https://doi.org/10.1096/fj.09134346.

[17] B. Ponsati, C. Carreno, V. Curto-Reyes, B. Valenzuela, M.J. Duart, W. Van Den Nest, O. Cauli, B. Beltran, J. Fernandez, F. Borsini, A. Caprioli, S. Di Serio, M. Veretchy, A. Baamonde, L. Menendez, F. Barros, P. de la Pena, R. Borges, V. Felipo, R. Planells-Cases, A. Ferrer-Montiel, An Inhibitor of Neuronal Exocytosis (DD04107) Displays Long-Lasting In Vivo Activity against Chronic Inflammatory and Neuropathic Pain, J. Pharmacol. Exp. Ther. 341 (2012) 634-645, https://doi org/10.1124/jpet.111.190678.

[18] C. Blanes-Mira, J. Clemente, G. Jodas, A. Gil, G. Fernandez-Ballester, B. Ponsati, L. Gutierrez, E. Perez-Paya, A. Ferrer-Montiel, A synthetic hexapeptide (Argireline) with antiwrinkle activity, Int. J. Cosmet. Sci. 24 (2002) 303-310, https://doi.org/ 10.1046/j.1467-2494.2002.00153.x.

[19] S.H. Lim, Y. Sun, T. Madanagopal Thiruvallur, V. Rosa, L. Kang, Enhanced Skin Permeation of Anti-wrinkle Peptides via Molecular Modification, Sci. Rep. 8 (2018) 1596, https://doi.org/10.1038/s41598-017-18454-z.

[20] A. Fernandez-Carvajal, R. Gonzalez-Muniz, G. Fernandez-Ballester, A. FerrerMontiel, Investigational drugs in early phase clinical trials targeting thermotransient receptor potential (thermoTRP) channels, Expert Opin. Investig. Drugs. 29 (2020) 1209-1222, https://doi.org/10.1080/13543784.2020.1825680.

[21] Q. Zhou, Y. Lai, T. Bacaj, M. Zhao, A.Y. Lyubimov, M. Uervirojnangkoorn, O. B. Zeldin, A.S. Brewster, N.K. Sauter, A.E. Cohen, S.M. Soltis, R. Alonso-Mori, M. Chollet, H.T. Lemke, R.A. Pfuetzner, U.B. Choi, W.I. Weis, J. Diao, T.C. Südhof, A.T. Brunger, Architecture of the synaptotagmin-SNARE machinery for neuronal exocytosis, Nature. 525 (2015) 62-67, https://doi.org/10.1038/nature14975.

[22] A. Zhou, K.D. Brewer, J. Rizo, Analysis of SNARE complex/synaptotagmin-1 interactions by one-dimensional NMR spectroscopy, Biochemistry. 52 (2013) 3446-3456, https://doi.org/10.1021/bi400230u.

[23] D. Fasshauer, M. Margittai, A Transient N-terminal Interaction of SNAP-25 and Syntaxin Nucleates SNARE Assembly, J. Biol. Chem. 279 (2004) 7613-7621, https://doi.org/10.1074/jbc.M312064200.

[24] C.A. Hood, G. Fuentes, H. Patel, K. Page, M. Menakuru, J.H. Park, Fast conventional Fmoc solid-phase peptide synthesis with HCTU, J. Pept. Sci. 14 (2008) 97-101, https://doi.org/10.1002/psc.921.

[25] M.I. Garcia-Aranda, Y. Mirassou, B. Gautier, M. Martin-Martinez, N. Inguimbert, M. Vidal, M.T. Garcia-Lopez, M.A. Jimenez, R. Gonzalez-Muniz, M.J. Perez de Vega, Disulfide and amide-bridged cyclic peptide analogues of the VEGF81-91 fragment: Synthesis, conformational analysis and biological evaluation, Bioorg. Med. Chem. 19 (2011) 7526-7533, https://doi.org/10.1016/j.bmc.2011.10.032.

[26] P. Morales, M.A. Jimenez, Design and structural characterisation of monomeric water-soluble $\alpha$-helix and $\beta$-hairpin peptides: State-of-the-art, Arch. Biochem. Biophys. 661 (2019) 149-167.

[27] D.S. Wishart, B.D. Sykes, F.M. Richards, Relationship between nuclear magnetic resonance chemical shift and protein secondary structure, J. Mol. Biol. 222 (1991) 311-333, https://doi.org/10.1016/0022-2836(91)90214-O.

[28] C.M. Santiveri, M. Rico, M.A. Jimenez, $13 \mathrm{C} \alpha$ and $13 \mathrm{C} \beta$ chemical shifts as a tool to delineate $\beta$-hairpin structures in peptides, J. Biomol. NMR. 19 (2001) 331-345.

[29] C. Solanas, B.G. de la Torre, M. Fernandez-Reyes, C.M. Santiveri, M.A. Jimenez, L. Rivas, A.I. Jimenez, D. Andreu, C. Cativiela, Sequence inversion and phenylalanine surrogates at the $\beta$-turn enhance the antibiotic activity of gramicidin S, J. Med. Chem. 53 (2010) 4119-4129, https://doi.org/10.1021/jm100143f.

[30] T. Cierpicki, J. Otlewski, Amide proton temperature coefficients as hydrogen bond indicators in proteins, J. Biomol. NMR. 21 (2001) 249-261.

[31] A.W. Hudson, M.J. Birnbaum, Identification of a nonneuronal isoform of synaptotagmin, Cell Biol. 92 (1995) 5895-5899, https://doi.org/10.1073/ pnas.92.13.5895.

[32] D.S. Wishart, C.G. Bigam, A. Holm, R.S. Hodges, B.D. Sykes, 1H, 13C and 15N random coil NMR chemical shifts of the common amino acids. I. Investigations of nearest-neighbor effects., J. Biomol. NMR. 5 (1995) 67-81. doi:10.1007/ BF00227471.

[33] K. Wuethrich, M. Billeter, W. Braun, Polypeptide secondary structure determination by nuclear magnetic resonance observation of short proton-proton distances, J. Mol. Biol. 180 (1984) 715-740, https://doi.org/10.1016/0022-2836 (84)90034-2.

[34] Y. Aoki, H. Mizoguchi, C. Watanabe, K. Takeda, T. Sakurada, S. Sakurada, Potential involvement of $\mu$-opioid receptor dysregulation on the reduced antinociception of morphine in the inflammatory pain state in mice, J. Pharmacol. Sci. (Tokyo, Japan) 124 (2014) 258-266, https://doi.org/10.1254/jphs.13242FP.

[35] V. Fernandez-Duenas, O. Pol, P. Garcia-Nogales, L. Hernandez, E. Planas, M. M. Puig, Tolerance to the antinociceptive and antiexudative effects of morphine in a murine model of peripheral inflammation, J. Pharmacol. Exp. Ther. 322 (2007) 360-368, https://doi.org/10.1124/jpet.106.118901.

[36] C. Watanabe, A. Komiyama, M. Yoshizumi, S. Sakurada, H. Mizoguchi, Morphine antinociception restored by use of methadone in the morphine-resistant inflammatory pain state, Front. Pharmacol. 11 (2020), 593647, https://doi.org/ 10.3389/fphar.2020.593647.

[37] H.J. Gould III, J.D. England, R.D. Soignier, P. Nolan, L.D. Minor, Z.P. Liu, S. R. Levinson, D. Paul, Ibuprofen blocks changes in Nav 1.7 and 1.8 sodium channels associated with complete Freund's adjuvant-induced inflammation in rat, J. Pain. 5 (2004) 270-280, https://doi.org/10.1016/j.jpain.2004.04.005.

[38] J. Wan, S. Nan, J. Liu, M. Ding, H. Zhu, C. Suo, Z. Wang, M. Hu, D. Wang, Y. Ding, Synaptotagmin 1 Is Involved in Neuropathic Pain and ElectroacupunctureMediated Analgesic Effect, Int. J. Mol. Sci. 21 (2020) 968, https://doi.org/ 10.3390/ijms21030968.

[39] LigPrep. Schrödinger, LCC, New York, NY, (2017).

[40] Protein Preparation Wizard 2017-3; Epik. Schrödinger, LCC, New York, NY, (2017); Impact, Schrödinger, LCC, New York, NY, 2017; Prime, Schrödinger , LCC,. New York, NY, (2017).

[41] G. Madhavi Sastry, M. Adzhigirey, T. Day, R. Annabhimoju, W. Sherman, Protein and ligand preparation: parameters, protocols, and influence on virtual screening enrichments, J. Comput. Aided. Mol. Des. 27 (2013) 221-234, https://doi.org/ 10.1007/s10822-013-9644-8.

[42] Schrödinger Suite 2017-3 Induce Fit Docking protocol, Glide, Schrödinger, LLC, New York, NY, (2017); Prime Version, Schrödinger, LLC. New York, NY, (2017).

[43] W. Sherman, H.S. Beard, R. Farid, Use of an induced fit receptor structure in virtual screening, Chem. Biol. Drug Des. 67 (2006) 83-84, https://doi.org/10.1111/ j.1747-0285.2005.00327.x.

[44] W. Sherman, T. Day, M.P. Jacobson, R.A. Friesner, R. Farid, Novel Procedure for Modeling Ligand/Receptor Induced Fit Effects, J. Med. Chem. 49 (2006) 534-553, https://doi.org/10.1021/jm050540c.

[45] A.Y. Lyubimov, M. Uervirojnangkoorn, O.B. Zeldin, Q. Zhou, M. Zhao, A. S. Brewster, T. Michels-Clark, J.M. Holton, N.K. Sauter, W.I. Weis, A.T. Brunger, Advances in X-ray free electron laser (XFEL) diffraction data processing applied to the crystal structure of the synaptotagmin-1 / SNARE complex, Elife. 5 (2016), e18740, https://doi.org/10.7554/elife.18740.

[46] P. Wongrattanakamon, P. Nimmanpipug, B. Sirithunyalug, S. Jiranusornkul, Molecular modeling elucidates the cellular mechanism of synaptotagmin-SNARE inhibition: a novel plausible route to anti-wrinkle activity of botox-like cosmetic active molecules, Mol. Cell. Biochem. 442 (2018) 97-109, https://doi.org/ 10.1007/s11010-017-3196-5.

[47] P.A. Case, D.A.; Cerutti, D.S.; Cheatham, III, T.E.; Darden, T.A.; Duke, R.E.; Giese, T.J.; Gohlke, H.; Goetz, A.W.; Greene, D.; Homeyer, N. ; Izadi, S.; Kovalenko, A.; Lee, T.S.; LeGrand, S.; Li, P.; Lin, C.; Liu, J.; Luchko, T.; Luo, R.; Mermelstein, D.; Mer, AMBER 2017, University of California, San Francisco, (2017).

[48] D.A. et al. Pearlman, "AMBER", a package of computer programs for applying molecular mechanics, normal mode analysis, molecular dynamics and free energy calculations to stimulate the structural and energetic properties of molecules. Comput. Phys. Commun. 91 (1995) 1-42.

[49] The PyMOL Molecular Graphics System, version 1. Schrödinger, LLC. (Schrödinger Inc., München, Germany), (n.d.).

[50] TOPSPIN, "NMR Data Acquisition and Processing Software, Bruker Biospin." Karlsruhe (Germany), (n.d.).

[51] D.S. Wishart, C.G. Bigam, J. Yao, F. Abildgaard, H.J. Dyson, E. Oldfield, J. L. Markley, B.D. Sykes, 1H, 13C and 15N chemical shift referencing in biomolecular NMR, J. Biomol. NMR. 6 (1995) 135-140, https://doi.org/10.1007/ BF00211777.

[52] K. Wüthrich, NMR of Proteins and Nucleic Acids, John Wiley \& Sons. New Jersey, USA, 1986.

[53] M.A. Jimenez, A.C. Barrachi-Saccilotto, E. Valdivia, M. Maqueda, M. Rico, Design, NMR characterization and activity of a 21-residue peptide fragment of bacteriocin AS-48 containing its putative membrane interacting region, J. Pept. Sci. 11 (2005) 29-36, https://doi.org/10.1002/psc.589.

[54] M.I. Garcia-Aranda, S. Gonzalez-Lopez, C.M. Santiveri, N. Gagey-Eilstein, M. Reille-Seroussi, M. Martin-Martinez, N. Inguimbert, M. Vidal, M.T. GarciaLopez, M.A. Jimenez, R. Gonzalez-Muniz, M.J. Perez de Vega, Helical peptides from VEGF and Vammin hotspots for modulating the VEGF-VEGFR interaction, Org. Biomol. Chem. 11 (2013) 1896-1905, https://doi.org/10.1039/c3ob27312a.

[55] S. Spera, A. Bax, Empirical correlation between protein backbone conformation and $C \alpha$ and $C \beta$ 13C nuclear magnetic resonance chemical shifts, J. Am. Chem. Soc. 113 (1991) 5490-5492, https://doi.org/10.1021/ja00014a071.

[56] P. Guntert, C. Mumenthaler, K. Wuthrich, Torsion angle dynamics for NMR structure calculation with the new program DYANA, J. Mol. Biol. 273 (1997) 283-298, https://doi.org/10.1006/jmbi.1997.1284.

[57] P. Guntert, Automated NMR protein structure calculation, Prog. Nucl. Magn. Reson. Spectrosc. 43 (2003) 105-125, https://doi.org/10.1016/S0079-6565(03) 00021-9.

[58] Y. Shen, A. Bax, Protein backbone and sidechain torsion angles predicted from NMR chemical shifts using artificial neural networks, J. Biomol. NMR. 56 (2013) 227-241, https://doi.org/10.1007/s10858-013-9741-y.

[59] D.G. Goddard, T.D.; and Kneller, SPARKY 3. Calif. Univ., (1999). 
[60] R. Koradi, M. Billeter, K. Wuethrich, MOLMOL: a program for display and analysis of macromolecular structures, J. Mol. Graph. 14 (1996) 51-55, https://doi.org/ 10.1016/0263-7855(96)00009-4.

[61] J. Ubach, Y. Lao, I. Fernandez, D. Arac, T.C. Suedhof, J. Rizo, The C2B Domain of Synaptotagmin I Is a Ca2+-Binding Module, Biochemistry. 40 (2001) 5854-5860, https://doi.org/10.1021/bi010340c.
[62] S. Sugita, W. Han, S. Butz, X. Liu, R. Fernandez-Chacon, Y. Lao, T.C. Sudhof, Synaptotagmin VII as a plasma membrane $\mathrm{Ca} 2+$ sensor in exocytosis, Neuron. 30 (2001) 459-473, https://doi.org/10.1016/S0896-6273(01)00290-2.

[63] L. Menendez, A. Lastra, A. Hidalgo, A. Baamonde, Unilateral hot plate test: a simple and sensitive method for detecting central and peripheral hyperalgesia in mice, J. Neurosci. Methods. 113 (2002) 91-97, https://doi.org/10.1016/S0165-0270 (01)00483-6. 